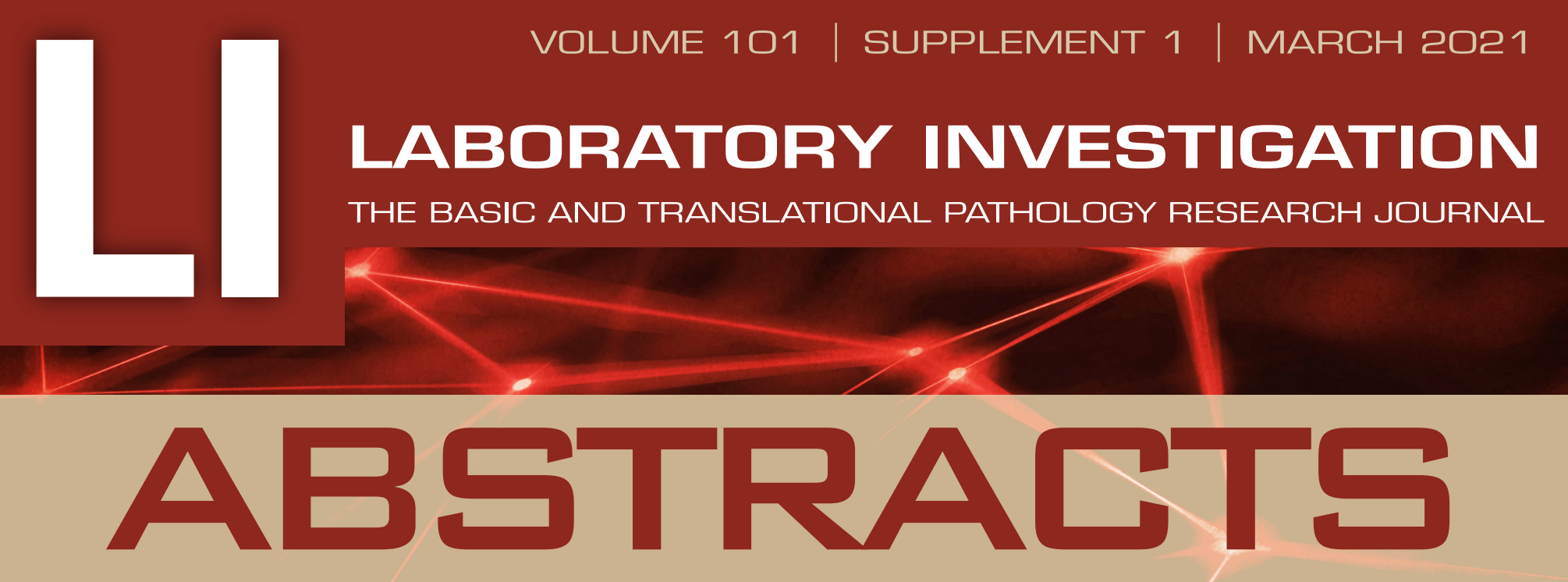

INFECTIOUS DISEASE PATHOLOGY (757-770)

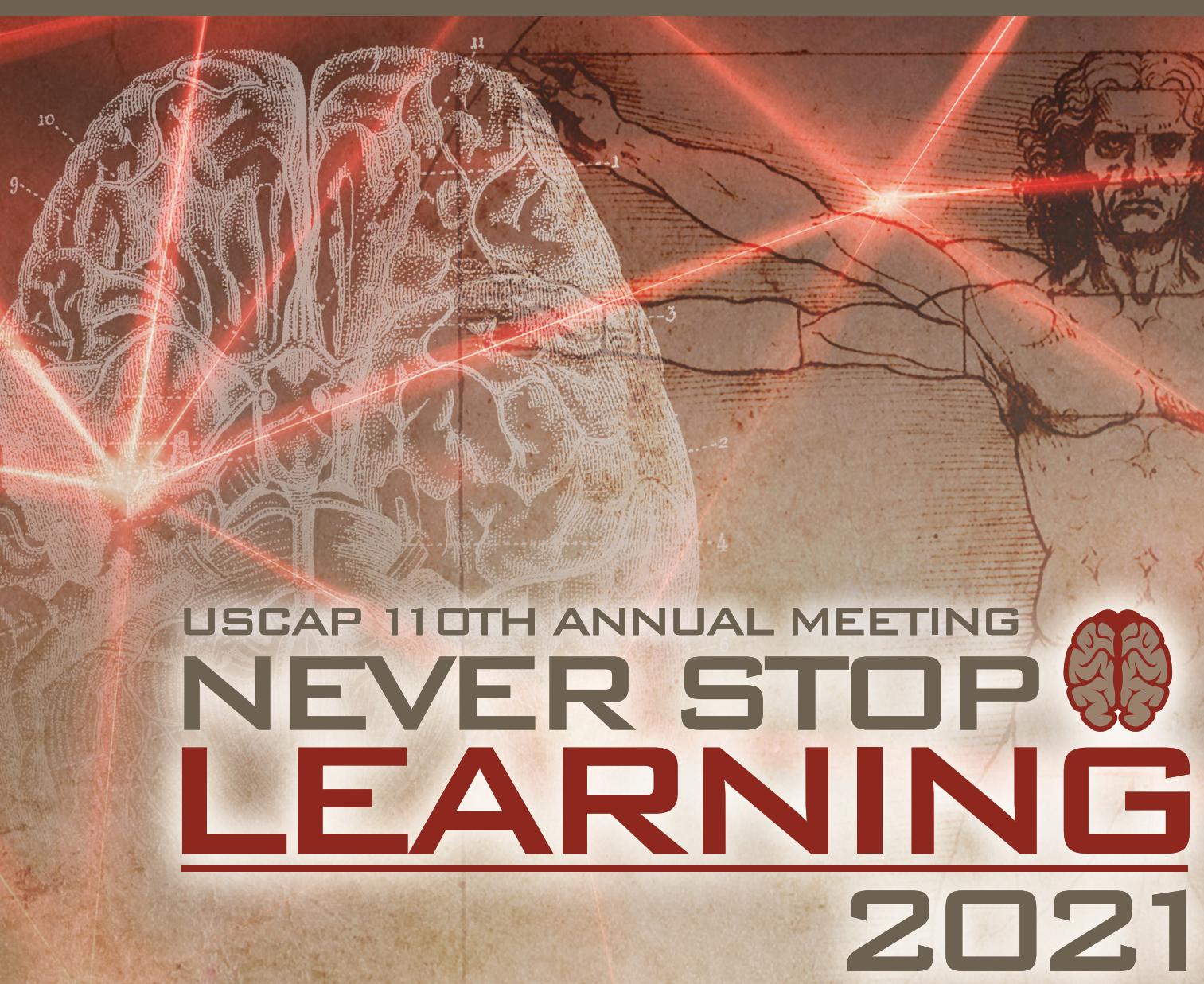

MARCH 13-18, 2021 VIRTUAL AND INTERACTIVE 


\section{EDUCATION COMMITTEE}

Jason L. Hornick

Chair

Rhonda K. Yantiss, Chair

Abstract Review Board and Assignment Committee

Kristin C. Jensen

Chair, CME Subcommittee
Laura C. Collins

Interactive Microscopy Subcommittee

Raja R. Seethala

Short Course Coordinator

Ilan Weinreb

Subcommittee for Unique Live Course Offerings

\author{
David B. Kaminsky \\ (Ex-Officio) \\ Zubair W. Baloch \\ Daniel J. Brat \\ Sarah M. Dry \\ William C. Faquin \\ Yuri Fedoriw \\ Karen Fritchie \\ Jennifer B. Gordetsky \\ Melinda Lerwill \\ Anna Marie Mulligan
}

\author{
Liron Pantanowitz \\ David Papke, \\ Pathologist-in-Training \\ Carlos Parra-Herran \\ Rajiv M. Patel \\ Deepa T. Patil \\ Charles Matthew Quick \\ Lynette M. Sholl \\ Olga K. Weinberg \\ Maria Westerhoff \\ Nicholas A. Zoumberos, \\ Pathologist-in-Training
}

\section{ABSTRACT REVIEW BOARD}

\author{
Benjamin Adam \\ Rouba Ali-Fehmi \\ Daniela Allende \\ Ghassan Allo \\ Isabel Alvarado-Cabrero \\ Catalina Amador \\ Tatjana Antic \\ Roberto Barrios \\ Rohit Bhargava \\ Luiz Blanco \\ Jennifer Boland \\ Alain Borczuk \\ Elena Brachtel \\ Marilyn Bui \\ Eric Burks \\ Shelley Caltharp \\ Wenqing (Wendy) Cao \\ Barbara Centeno \\ Joanna Chan \\ Jennifer Chapman \\ Yunn-Yi Chen \\ Hui Chen \\ Wei Chen \\ Sarah Chiang \\ Nicole Cipriani \\ Beth Clark \\ Alejandro Contreras \\ Claudiu Cotta \\ Jennifer Cotter \\ Sonika Dahiya \\ Farbod Darvishian \\ Jessica Davis \\ Heather Dawson \\ Elizabeth Demicco \\ Katie Dennis \\ Anand Dighe \\ Suzanne Dintzis \\ Michelle Downes
}

Charles Eberhart Andrew Evans

Julie Fanburg-Smith Michael Feely

Dennis Firchau

Gregory Fishbein

Andrew Folpe

Larissa Furtado

Billie Fyfe-Kirschner

Giovanna Giannico

Christopher Giffith

Anthony Gill

Paula Ginter

Tamar Giorgadze

Purva Gopal

Abha Goyal

Rondell Graham

Alejandro Gru

Nilesh Gupta

Mamta Gupta

Gillian Hale

Suntrea Hammer

Malini Harigopal

Douglas Hartman

Kammi Henriksen

John Higgins

Mai Hoang

Aaron Huber

Doina Ivan

Wei Jiang

Vickie Jo

Dan Jones

Kirk Jones

Neerja Kambham

Dipti Karamchandani

Nora Katabi

Darcy Kerr

Francesca Khani
Joseph Khoury

Rebecca King

Veronica Klepeis

Christian Kunder

Steven Lagana

Keith Lai

Michael Lee

Cheng-Han Lee

Madelyn Lew

Faqian Li

Ying Li

Haiyan Liu

Xiuli Liu

Lesley Lomo

Tamara Lotan

Sebastian Lucas

Anthony Magliocco

Kruti Maniar

Brock Martin

Emily Mason

David McClintock Anne Mills

Richard Mitchell

Neda Moatamed

Sara Monaco

Atis Muehlenbachs Bita Naini

Dianna Ng

Tony $\mathrm{Ng}$

Michiya Nishino

Scott Owens

Jacqueline Parai

Avani Pendse

Peter Pytel

Stephen Raab

Stanley Radio

Emad Rakha

Robyn Reed
Michelle Reid

Natasha Rekhtman

Jordan Reynolds

Andres Roma

Lisa Rooper

Avi Rosenberg

Esther (Diana) Rossi

Souzan Sanati

Gabriel Sica

Alexa Siddon

Deepika Sirohi

Kalliopi Siziopikou

Maxwell Smith

Adrian Suarez

Sara Szabo

Julie Teruya-Feldstein

Khin Thway

Rashmi Tondon

Jose Torrealba

Gary Tozbikian

Andrew Turk

Evi Vakiani

Christopher VandenBussche

Paul VanderLaan

Hannah Wen

Sara Wobker

Kristy Wolniak

Shaofeng Yan

Huihui Ye

Yunshin Yeh

Anjana Yeldandi

Gloria Young

Lei Zhao

Minghao Zhong

Yaolin Zhou

Hongfa Zhu

To cite abstracts in this publication, please use the following format: Author A, Author B, Author C, et al. Abstract title (abs\#). In "File Title." Laboratory Investigation 2021; 101 (suppl 1): page\# 
757 HPV16/18 and p16 Gene Expression in Ocular Surface Squamous Neoplasia: a Retrospective Analysis of $\mathbf{4 9}$ cases from Zimbabwe, Africa

Maria Carolina Beeter ${ }^{1}$, Jonathan Lin ${ }^{2}$, Yu-Tsueng Liu ${ }^{3}$, Lisa Centeno, Ahmed Ali ${ }^{4}$, Lovemore Gwanzura ${ }^{5}$, Robert Schooley ${ }^{3}$, Rangarirai Masanganise ${ }^{5}$

${ }^{1}$ Stanford Health Care, Stanford, CA, ${ }^{2}$ Stanford Hospital, Stanford, CA, ${ }^{3}$ University of California, San Diego, San Diego, CA, ${ }^{4}$ Stanford Health Care, Palo Alto, CA, ${ }^{5}$ University of Zimbabwe, Harare, Zimbabwe

Disclosures: Maria Carolina Beeter: None; Jonathan Lin: None; Ahmed Ali: None

Background: Human papillomavirus (HPV) infection is an important risk factor for squamous neoplasms of the cervix, head, and neck. HPV's role in ocular surface squamous neoplasia (OSSN), including conjunctival intraepithelial neoplasia (CIN) and squamous cell carcinoma(SCC), is controversial. HIV-seropositive (HSP) populations have increased susceptibility to HPV infections, HPV-linked cancers, and markedly increased prevalence of OSSN. To determine if OSSN was related to high-risk HPV 16/18 infection in HSP patients, we performed a retrospective, cross-sectional qRT-PCR analysis of 49 OSSN patient biopsies for expression of HPV 16/18 E6/E7 viral oncogenes and the p16 tumor suppressor gene in these samples.

Design: OSSN biopsies were resected from 49 Zimbabwean patients (28 female, 21 male, ages 18-67 years), of whom 43 were HIV-seropositive (HSP). Part of each biopsy was formalin fixed, paraffin-embedded, cut, and stained with hematoxylin and eosin (H\&E) to diagnose OSSN and classify as CIN or SCC. Nucleic acid was extracted from the remaining unfixed biopsy tissues and assayed by quantitative RT-PCR for p16 and HPV 16/18 E6/E7 gene transcript expression. HeLa, CaSki, and SiHa cells constitutively expressing HPV oncogenes served as positive controls. HeLa cells were also used as positive control for p16 expression, with positivity defined as p16 delta CT $<10.3727$ cycles. Statistical analysis of data was performed using software MedCalc v. 19. KolmogorovSmirnov test was performed to confirm normal distribution (parametric data). One-way ANOVA was used to compare quantitative variables. Chi-squared test was used to compare qualitative variables. The significance of the results was assessed in the form of $P$-value that was differentiated into non-significant when P-value $>0.05$; significant when P-value $\leq 0.05$; and highly significant when P-value $\leq 0.01$.

Results: CIN was diagnosed in 19 of 49 OSSN biopsies (39\%), and SCC in 30 of 49 biopsies (61\%). Within the $43 / 49$ HSP patients, CIN was diagnosed in 14/43 cases and SCC in 29/43 cases. All 49 OSSN cases (CIN and SCC) were negative for both HPV 16 and 18 E6/E7 oncogenes. p16 expression was detected in 13/49 OSSN cases ( 7 CIN cases; and 6 SCC cases). 11/13 OSSN patients that were p16+ were also HSP (5 CIN cases and 6 SCC cases); while 1/13 OSSN patient was p16+ and HIV-seronegative. 1 patient was described as HIV status "Indeterminant." No statistically significant difference was found in OSSN occurrence between men and women, chi-square test $(p>0.05)$. No statistically significant difference in $p 16$ gene expression was found between subtypes of OSSNs (e.g., CIN vs SCC), analyzed by ANOVA ( $p>0.05)$. There was insufficient power to calculate statistical significant differences between HSP and HIV-seronegative cohorts.

Conclusions: Consistent with prior studies, we found that OSSN affects men and women with no predominance in either gender. Contrary to other studies, we found no expression of high-risk HPV 16/18 E6/E7 viral gene expression in our OSSN cohort. Increased p16 gene expression was found in a minority of OSSN cases

\section{Seroprevalence of SARS-CoV-2 IgG Antibodies in Health Care Workers at an Academic Medical Center in Boston, Massachusetts}

Manisha Cole ${ }^{1}$, Yachana Kataria², Elizabeth Duffy², Kyle de la Cena ${ }^{3}$, Elissa Perkins ${ }^{2}$, Tara Bouton ${ }^{4}$, Martha Werler ${ }^{4}$, Cassandra Pierre ${ }^{2}$, Karen Jacobson ${ }^{4}$, Elizabeth Ragan, Christopher Andry ${ }^{2}$

${ }^{1}$ Boston University School of Medicine/Boston Medical Center, Boston, MA, ${ }^{2}$ Boston Medical Center, Boston, MA, ${ }^{3}$ Boston University School of Medicine, Boston, MA, ${ }^{4}$ Boston University, Boston, MA

\section{Disclosures: Manisha Cole: None}

Background: Severe acute respiratory syndrome coronavirus-2 (SARS-CoV-2) is a novel virus that causes Coronavirus disease 2019 (COVID-19). COVID-19 has infected over 124,813 and caused the deaths of at least 600 healthcare workers (HCWs) in the United States as of October 11th, 2020. Boston's surge was early April to midMay, with as many as 237 COVID-19 positive patients admitted per day, a $50 \%$ rate. Seroprevalence studies are 
important since the proportion of individuals that are asymptomatic with SARS-CoV-2 remains unknown and this assessment could lead to understanding disease transmission rates. HCWs are in a high-risk setting. It is important to understand disease burden among this population as it can help identify areas of high risk and inform infection control policy to slow infection rates. We aim to assess the seroprevalence of SARS-CoV-2 among HCWs at our Boston area hospital.

Design: Eligible HCWs were over 18 years old and worked on campus during the surge. With IRB approval, subjects provided consent, and completed a questionnaire regarding sociodemographic, occupation, COVID exposure, and infection prevention measures by using REDCap ${ }^{\circledR}$ database. Participants had their blood drawn between July 13th - 26th for qualitative COVID-19 IgG antibody testing. Analyses were performed by the clinical pathology laboratory, detecting IgG antibody against the SARS-CoV-2 nucleoprotein on EUA approved assay.

Results: The HCWs overall seroprevalence rate was $5.45 \%$. Participants that were seropositive were more likely to be younger, female, and non-smokers. Obese participants had significantly higher odds of being seropositive (OR: 1.97 (95\% Cl: 1.25 - 3.32). Nurses (OR: 1.29 (95\% Cl: 0.64-3.08)) and patient facing allied health ((OR: 1.61 (95\% Cl: 0.74-4.22)) were more likely to be seropositive.

$75.3 \%$ of participants with a positive RT-PCR test were seropositive, while $2 \%$ with a negative RT-PCR test were seropositive. $1.8 \%$ with no prior RT-PCR testing were seropositive.

Seropositivity status was significantly associated with fever, cough, shortness of breath, chills, myalgia, loss of appetite, smell and taste, and lack of physical distancing with co-workers.

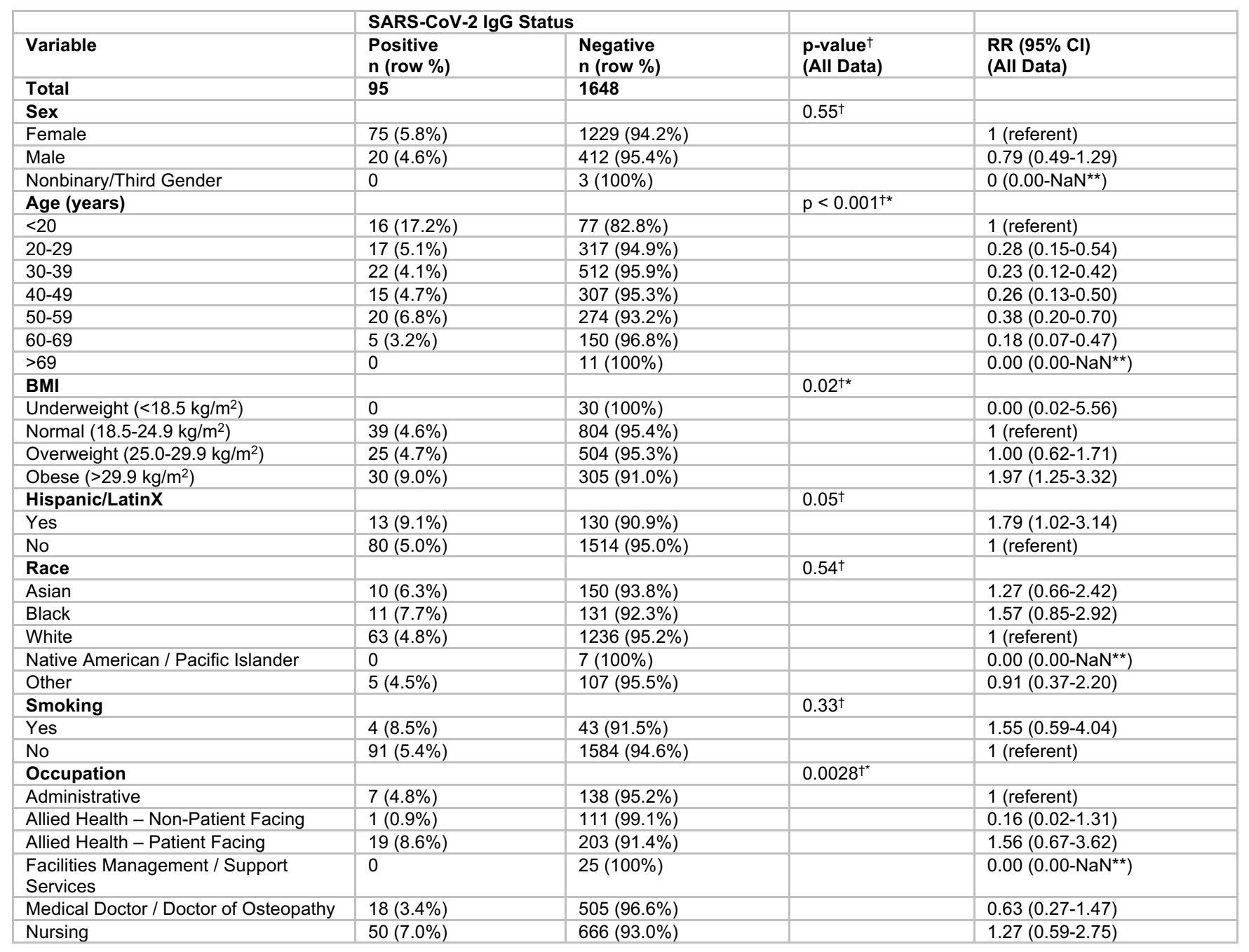


Conclusions: These results support efficacy of hand hygiene and PPE, highlighting the need to reinforce these practices when engaging with colleagues. Nurses and allied HCWs were more likely to be seropositive, likely due to frequency of exposure to positive patients or relaxed distancing among coworkers. This data suggests a higher prevalence of milder symptoms that do not always prompt caution or changes in daily activities.

\section{Diagnostic Accuracy of Histochemical Stains in Identification of Mucormycetes Nibras Fakhri ${ }^{1}$, Gordon Love ${ }^{1}$ ${ }^{1}$ Louisiana State University Health Sciences Center, New Orleans, LA}

Disclosures: Nibras Fakhri: None; Gordon Love: None

Background: Mucormycosis infection is often associated with pulmonary and disseminated disease with high mortality. Mucormycosis is a rapidly invasive disease with tissue infraction secondary to angioinvasion and fungal elements may not be readily recognizable within the resulting necrotic material. We compared the diagnostic accuracy of hematoxylin-eosin(H\&E) as well as the customarily used "fungus stains"(GMS and PAS) on tissue sections from mucormycosis cases.

Design: We evaluated a total of 13 cases with invasive mucormycosis infection involving the lung, brain, spleen and the skin. Two cases are from University Medical center, New Orleans, the other 11 cases were collected from hospitals in Sacramento, California. We reviewed the histopathology of sections stained with hematoxylineosin(H\&E), Gomori methenamine silver (GMS) and periodic acid-schiff (PAS) stains. All sections were examined carefully for fungal hyphae. We graded the intensity of GMS staining from 1+(poor), 2-3+(boarderline) and $4+$ (strong).

Results: Histopathologically, the most prevalent feature of mucormycetes infection was the presence of abundant necrosis, angioinvasion and tissue infraction. Careful examination revealed a thin walled, slender, broad, sparsely aseptate hyphae characteristic of mucomycetes. GMS stain ranged from $1+($ poor) in $6 / 13$ cases (46.1\%); 2 $3+($ boarderline) in 2/13 (15.3\%); and 4+(strong) in 5/13 (38.5\%). PAS stain and H\&E have the highest diagnostic performance in most cases.

\begin{tabular}{|r|l|l|l|l|l|}
\hline Case \# & Age & Sex & Site & GMS stain & Clinical history \\
\hline 1. & 42 & $\mathrm{~F}$ & Skin, knee & $4+$ & Right leg amputation due to truma \\
\hline 2. & 52 & $\mathrm{~F}$ & Skin, left cheek & $1+$ & Acute myeloid leukemia \\
\hline 3. & 58 & $\mathrm{M}$ & Skin & $1+$ & Calf cyst \\
\hline 4. & 52 & $\mathrm{~F}$ & Skin & $1+$ & Left cheek debridement \\
\hline 5. & 79 & $\mathrm{M}$ & Skin & $1+$ & Leukemia \\
\hline 6. & 52 & $\mathrm{~F}$ & Brain & $1+$ & IV drug abuse and hepatitis C \\
\hline 7. & 65 & $\mathrm{M}$ & Lung & $2-3+$ & Fever and pulmonary consolidation \\
\hline 8. & 34 & $\mathrm{M}$ & Lung & $1+$ & Empyema \\
\hline 9. & 89 & $\mathrm{M}$ & Bone & $4+$ & Ethmoid bone \\
\hline 10. & 80 & $\mathrm{M}$ & Lung & $2-3+$ & Acute myeloid leukemia \\
\hline 11. & 46 & $\mathrm{M}$ & Lung, spleen & $4+$ & Empyema \\
\hline 12. & 54 & $\mathrm{M}$ & Lung & $4+$ & $\begin{array}{l}\text { Acute myeloid leukemia with pleural } \\
\text { effusion }\end{array}$ \\
\hline & & & & & Diabetes mellitus and hypertension \\
\hline 13. & 73 & $\mathrm{M}$ & Rhino-cerebral & $4+$ & \\
\hline
\end{tabular}


Figure 1 - 759

$H \& E, 40 x$
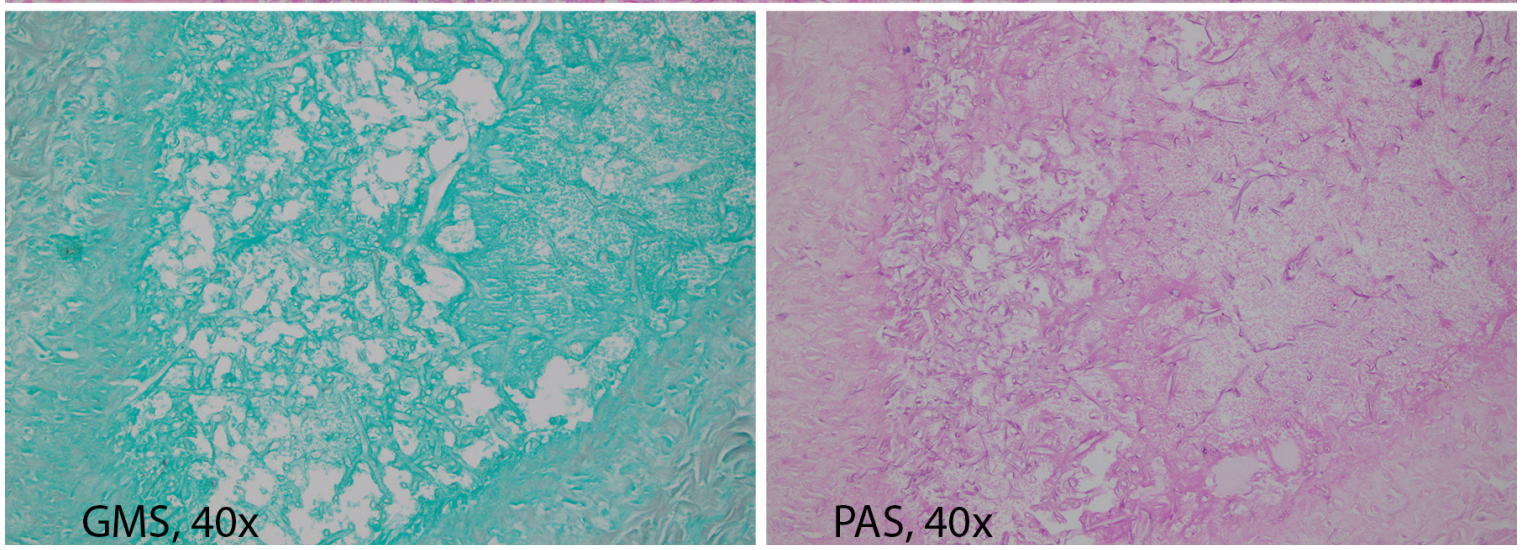

Conclusions: The thin, delicate fungal hyphae embedded within the necrotic tissue and vascular lumen can be missed particularly when scanning a low magnification. Reliance upon GMS staining, the mainstay for fungal histodiagnosis, may lead to underdiagnosis of the mucormycetes. The PAS stain was better than the GMS stain that demonstrated the most limitation for staining mucormycete hyphae. PAS and H\&E staining are superior for detection the mucormycetes in tissue, as early diagnosis and treatment improve patient outcome.

\section{Isolated Laryngeal Cryptococcus Neoformans Infection in Immunocompetent Patients: Case Report and Literature Review \\ Karina Furlan ${ }^{1}$, Ritu Ghai ${ }^{2}$ \\ ${ }^{1}$ Rush University Medical Center, Chicago, IL, ${ }^{2}$ Advocate Christ Medical Center, Chicago, IL}

Disclosures: Karina Furlan: None

Background: Laryngeal chronic cryptococcal infection has been increasingly described among immunocompetent individuals (1). It is acquired by inhalation of Cryptococcus neoformans yeasts from contaminated soil with avian excrement and generally causes a self-limited subacute pulmonary infection in immunocompetent hosts (2). Isolated laryngeal infection is rare; clinically it presents with hoarseness and is described in patients in chronic use of inhaled steroids either with COPD, asthma or with no known comorbidity (2-18).

Design: The authors present a case of isolated laryngeal cryptococcosis in a 70-year-old COPD patient and conduct a literature review in three databases: PubMed, google scholar and Scielo. The search was conducted using the following terms: "cryptococcus neoformans", "cryptococcosis", "larynx" and "vocal cord. Exclusion criteria were immunosuppression and/or systemic disease.

Results: The current case concerns a 70-year-old male with past medical history of COPD on chronic use of inhaled steroids who developed hoarseness refractory to oral prednisone. Direct laryngoscopy revealed an erythematous mucosa (Image 1) and a sessile mass that was excised for histological examination. Section on H\&E 
showed mild chronic inflammation, edema and encapsulated yeast forms highlighted by GMS and mucicarmine (Image 2).

Literature review revealed 18 peer-reviewed articles with a total of 21 patients (including the current one), M:F ratio was 9:12, median age was 69 years old, 8 patients had history of COPD and 6 had history of asthma. 20/21 patients $(95 \%)$ had hoarseness as initial symptom, other symptoms included cough and laryngotracheobronchitis in one patient. 13/61 (62\%) patients were chronically using inhaled steroids. The laryngoscopic findings included: white exudative patches $(8,11,13,14,16,19)$, erythema $(9,12)$, warty-like lesion $(3)$, cystic lesion $(5)$, sessile or polypoid lesion $(12,17,20)$, "wave"-like lesion (4), asymmetry $(18)$, thickened mucosa $(14)$ or hyperkeratotic lesion resembling a carcinoma $(6,7)$. White plaques were the most common finding in $6 / 21(28.5 \%)$ cases. All patients had complete resolution of the infection after variable period of oral antifungal therapy. (Table 1: compilation of all cases reported in the literature to date).

\begin{tabular}{|c|c|c|c|c|c|c|c|c|c|c|}
\hline $\begin{array}{l}\text { Author, } \\
\text { date }\end{array}$ & Organism & $\begin{array}{l}\text { Number } \\
\text { of } \\
\text { patients }\end{array}$ & Gender & $\underset{*}{\text { Age }}$ & Comorbidity & $\begin{array}{l}\text { Current } \\
\text { medications }\end{array}$ & Location & Symptoms & Treatment & Follow-up \\
\hline $\begin{array}{l}\text { Reese and } \\
\text { Colcasure } \\
1975(11)\end{array}$ & $\begin{array}{l}\text { Cryptococcus } \\
\text { neoformans }\end{array}$ & 1 & Male & 47 & None & None & $\begin{array}{l}\text { Multiple } \\
\text { exudative } \\
\text { lesion } \\
\text { extending to } \\
\text { trachea }\end{array}$ & Hoarseness & $\begin{array}{l}\text { Oral fluconazole } \\
2 \text { months }\end{array}$ & $\begin{array}{l}\text { Complete } \\
\text { resolution in } 2 \\
\text { moths }\end{array}$ \\
\hline $\begin{array}{l}\text { Smallman } \\
\text { et al, } \\
1989(3)\end{array}$ & $\begin{array}{l}\text { Cryptococcus } \\
\text { neoformans }\end{array}$ & 1 & Female & 31 & None & None & $\begin{array}{l}\text { Warty lesion on } \\
\text { the level of right } \\
\text { vocal cord } \\
\text { measuring } 0.5 \mathrm{x} \\
0.5 \mathrm{~cm}\end{array}$ & Hoarseness & Refused & Not available \\
\hline $\begin{array}{l}\text { Kershner et } \\
\text { al, } 1995 \text { (4) }\end{array}$ & $\begin{array}{l}\text { Cryptococcus } \\
\text { neoformans }\end{array}$ & 1 & Male & 61 & $\begin{array}{l}\text { COPD, Insulin- } \\
\text { dependent } \\
\text { Diabetes Mellitus, } \\
\text { 35-pack-year } \\
\text { history of cigarette } \\
\text { smoking, alcohol } \\
\text { abuse }\end{array}$ & $\begin{array}{l}\text { Prednisone } 60 \\
\text { mg/day }\end{array}$ & $\begin{array}{l}\text { Wave } \\
\text { abnormality on } \\
\text { mucosal } \\
\text { surface }\end{array}$ & Hoarseness & $\begin{array}{l}\text { 6-week course } \\
\text { of fluconazole } \\
\text { with complete } \\
\text { resolution of the } \\
\text { lesion }\end{array}$ & $\begin{array}{l}\text { After several } \\
\text { months, no } \\
\text { lesion, some } \\
\text { hoarseness } \\
\text { persisted }\end{array}$ \\
\hline $\begin{array}{l}\text { Frisch and } \\
\text { Gnepp } \\
1995(12)\end{array}$ & $\begin{array}{l}\text { Cryptococcus } \\
\text { neoformans }\end{array}$ & 1 & Male & 73 & $\begin{array}{l}\text { Diabetes Mellitus, } \\
\text { COPD }\end{array}$ & None & $\begin{array}{l}\text { Hyperemic and } \\
\text { fusiform mass }\end{array}$ & Hoarseness & $\begin{array}{l}\text { Fluconazole } 1.5 \\
\text { months }\end{array}$ & $\begin{array}{l}\text { Symptomatic } \\
\text { resolution } \\
\text { after } \\
\text { resection. }\end{array}$ \\
\hline $\begin{array}{l}\text { Isaacson } \\
\text { and Frable } \\
1996(19) \\
\end{array}$ & $\begin{array}{l}\text { Cryptococcus } \\
\text { neoformans }\end{array}$ & 1 & Male & 87 & COPD & $\begin{array}{l}\text { Inhaled } \\
\text { steroid }\end{array}$ & $\begin{array}{l}\text { Exudative white } \\
\text { lesion on true } \\
\text { vocal cord }\end{array}$ & Hoarseness and dry couch & $\begin{array}{l}\text { Oral fluconazole } \\
2 \text { months }\end{array}$ & $\begin{array}{l}\text { Complete } \\
\text { resolution at } 2 \\
\text { months }\end{array}$ \\
\hline $\begin{array}{l}\text { Chebbo et } \\
\text { al, } \\
2001(20)\end{array}$ & $\begin{array}{l}\text { Cryptococcus } \\
\text { neoformans }\end{array}$ & 1 & Female & 66 & Asthma & $\begin{array}{l}\text { Inhaled and } \\
\text { oral steroid }\end{array}$ & $\begin{array}{l}\text { Laryngeal } \\
\text { friable mass }\end{array}$ & Hoarseness & $\begin{array}{l}\text { Tracheostomy, } \\
\text { oral fluconazole }\end{array}$ & Not available \\
\hline $\begin{array}{l}\text { Nadrous et } \\
\text { al } 2004 \text { (13) }\end{array}$ & $\begin{array}{l}\text { Cryptococcus } \\
\text { neoformans }\end{array}$ & 1 & Male & 55 & $\begin{array}{l}\text { Asthma and allergic } \\
\text { fungal sinusitis }\end{array}$ & $\begin{array}{l}\text { Inhaled } \\
\text { steroids }\end{array}$ & $\begin{array}{l}\text { Leukoplakia } \\
\text { with } \\
\text { surrounding } \\
\text { erythema }\end{array}$ & Hoarseness and couch & $\begin{array}{l}\text { Fluconazole } \\
\text { followed by } \\
\text { Itraconazole }\end{array}$ & $\begin{array}{l}\text { Complete } \\
\text { resolution in } 4 \\
\text { months }\end{array}$ \\
\hline $\begin{array}{l}\text { Bamba et } \\
\text { al, } 2005 \text { (5) }\end{array}$ & $\begin{array}{l}\text { Cryptococcus } \\
\text { neoformans }\end{array}$ & 1 & Female & 68 & None & None & Cyst & Hoarseness & Cystectomy & $\begin{array}{l}\text { No symptoms } \\
\text { on 2-year- } \\
\text { follow-up visit }\end{array}$ \\
\hline \multirow[t]{2}{*}{$\begin{array}{l}\text { Gordon et } \\
\text { al, } \\
2010(14)\end{array}$} & \multirow[t]{2}{*}{$\begin{array}{l}\text { Cryptococcus } \\
\text { neoformans }\end{array}$} & 1 & Male & 64 & Asthma & $\begin{array}{l}\text { Inhaled } \\
\text { steroids }\end{array}$ & $\begin{array}{l}\text { Patchy } \\
\text { leukoplakia }\end{array}$ & Hoarseness & $\begin{array}{l}\text { Oral fluconazole } \\
10 \text { months }\end{array}$ & $\begin{array}{l}\text { By the end of } \\
\text { treatment } \\
\text { complete } \\
\text { resolution }\end{array}$ \\
\hline & & 1 & Female & 79 & None & $\begin{array}{l}\text { Inhaled } \\
\text { steroids }\end{array}$ & $\begin{array}{l}\text { True vocal cord } \\
\text { thickening }\end{array}$ & Hoarseness & $\begin{array}{l}\text { Oral fluconazole } \\
6 \text { months }\end{array}$ & $\begin{array}{l}\text { Complete } \\
\text { resolution }\end{array}$ \\
\hline $\begin{array}{l}\text { Ihenachor } \\
\text { et al, } \\
2016 \text { (15) }\end{array}$ & $\begin{array}{l}\text { Cryptococcus } \\
\text { neoformans }\end{array}$ & 1 & Female & 82 & COPD & $\begin{array}{l}\text { Inhaled } \\
\text { steroid }\end{array}$ & $\begin{array}{l}\text { Diffuse } \\
\text { ulcerative mass } \\
\text { on false and } \\
\text { true vocal cord, } \\
\text { granuloma }\end{array}$ & Hoarseness and stridor & $\begin{array}{l}\text { Itraconazole } 6 \\
\text { week-course } \\
\text { followed by } \\
\text { Pulsed-dye } \\
\text { laser therapy } \\
\text { ablation and } \\
\text { oral fluconazole } \\
2 \text { months }\end{array}$ & $\begin{array}{l}\text { Complete } \\
\text { resolution at } \\
\text { month } 7\end{array}$ \\
\hline $\begin{array}{l}\text { Menon et } \\
\text { al, } \\
2016(16)\end{array}$ & $\begin{array}{l}\text { Cryptococcus } \\
\text { neoformans }\end{array}$ & 1 & Female & 80 & COPD & $\begin{array}{l}\text { Inhaled } \\
\text { steroid }\end{array}$ & $\begin{array}{l}\text { Laryngeal } \\
\text { inflammation } \\
\text { and erythema } \\
\text { with white } \\
\text { patches } \\
\text { bilaterally true } \\
\text { vocal cords }\end{array}$ & Laryngotracheobronchitis & $\begin{array}{l}\text { Fluconazole } 6 \\
\text { months }\end{array}$ & $\begin{array}{l}\text { Complete } \\
\text { resolution on } \\
\text { month } 6\end{array}$ \\
\hline $\begin{array}{l}\text { Chang et al, } \\
2013(17)\end{array}$ & $\begin{array}{l}\text { Cryptococcus } \\
\text { neoformans }\end{array}$ & 1 & Male & 53 & Pigeon exposure & None & $\begin{array}{l}\text { Posterior true } \\
\text { vocal cord } \\
\text { mass }\end{array}$ & Hoarseness & $\begin{array}{l}\text { Fluconazole } 1.5 \\
\text { months }\end{array}$ & $\begin{array}{l}\text { Complete } \\
\text { resolution } \\
\text { after } \\
\text { completion } \\
\text { therapy }\end{array}$ \\
\hline $\begin{array}{l}\text { Mittal et al, } \\
2013(6)\end{array}$ & $\begin{array}{l}\text { Cryptococcus } \\
\text { neoformans }\end{array}$ & 1 & Male & 58 & None & None & $\begin{array}{l}\text { Irregular red } \\
\text { lesion on the } \\
\text { right vocal cord, } \\
\text { suspicious for } \\
\text { carcinoma }\end{array}$ & Hoarseness & $\begin{array}{l}\text { Fluconazole } \\
400 \mathrm{mg} / \text { daily }\end{array}$ & $\begin{array}{l}\text { Complete } \\
\text { resolution } \\
\text { after } 12 \\
\text { months of } \\
\text { treatment }\end{array}$ \\
\hline $\begin{array}{l}\text { Tamagawa } \\
\text { et al, } \\
2015 \text { (7) }\end{array}$ & $\begin{array}{l}\text { Cryptococcus } \\
\text { neoformans }\end{array}$ & 1 & Female & 82 & $\begin{array}{l}\text { COPD, Rheumatoid } \\
\text { arthritis }\end{array}$ & $\begin{array}{l}\text { Long-term } \\
\text { steroid } \\
\text { treatment }\end{array}$ & $\begin{array}{l}\text { Exudative, } \\
\text { irregular region } \\
\text { on the right } \\
\text { arytenoid, } \\
\text { mimicking a } \\
\text { laryngeal } \\
\text { carcinoma } \\
\end{array}$ & Chronic hoarseness & $\begin{array}{l}\text { Fluconazole } \\
200 \mathrm{mg} / \mathrm{daily}\end{array}$ & $\begin{array}{l}\text { Complete } \\
\text { healing after } 6 \\
\text { months }\end{array}$ \\
\hline $\begin{array}{l}\text { Bergeron et } \\
\text { al, } 2015 \text { (8) }\end{array}$ & $\begin{array}{l}\text { Cryptococcus } \\
\text { neoformans }\end{array}$ & 1 & Female & 78 & $\begin{array}{l}\text { Asthma } \\
\text { Atrial fibrillation } \\
\text { Gastroesophageal } \\
\text { reflux }\end{array}$ & $\begin{array}{l}\text { Inhaled } \\
\text { budesonide } \\
\text { Warfarin } \\
\text { Pantoprazole }\end{array}$ & $\begin{array}{l}\text { Whitish vocal } \\
\text { and } \\
\text { hyperkeratosis }\end{array}$ & Chronic hoarseness & $\begin{array}{l}\text { Fluconazole } \\
200 \mathrm{mg} \text { twice } \\
\text { daily ad } \\
\text { reduction of } \\
\text { steroid dose }\end{array}$ & $\begin{array}{l}\text { Complete } \\
\text { resolution } \\
\text { after } 4 \text { months } \\
\text { of treatment }\end{array}$ \\
\hline
\end{tabular}




\begin{tabular}{|c|c|c|c|c|c|c|c|c|c|c|}
\hline $\begin{array}{l}\text { Jeng et al, } \\
2016 \text { (10) }\end{array}$ & $\begin{array}{l}\text { Cryptococcus } \\
\text { neoformans }\end{array}$ & 1 & Female & 71 & COPD & $\begin{array}{l}\text { Inhaled } \\
\text { steroid }\end{array}$ & $\begin{array}{l}\text { White exophytic } \\
\text { patches on true } \\
\text { vocal cords } \\
\text { bilaterally }\end{array}$ & $\begin{array}{l}\text { Cough and worsening of } \\
\text { the hoarseness }\end{array}$ & $\begin{array}{l}\text { KTP laser } \\
\text { ablation and } \\
\text { fluconazole } \\
\text { therapy for } \\
4 \text { months }\end{array}$ & $\begin{array}{l}\text { No recurrence } \\
\text { of disease } \\
\text { after } 11 \\
\text { months. }\end{array}$ \\
\hline $\begin{array}{l}\text { Dangol et } \\
\text { al, } \\
2017 \text { (18) }\end{array}$ & $\begin{array}{l}\text { Cryptococcus } \\
\text { neoformans }\end{array}$ & 1 & Female & 83 & None & $\begin{array}{l}\text { Inhaled } \\
\text { steroids }\end{array}$ & $\begin{array}{l}\text { Nodular } \\
\text { asymmetry and } \\
\text { irregular } \\
\text { mucosa left true } \\
\text { vocal cord }\end{array}$ & Chronic hoarseness & $\begin{array}{l}\text { Fluconazole } 6 \\
\text { months }\end{array}$ & $\begin{array}{l}\text { Improvement } \\
\text { after } 3 \text { weeks } \\
\text { noted }\end{array}$ \\
\hline \multirow{2}{*}{$\begin{array}{l}\text { Wong et al, } \\
2017 \text { (9) }\end{array}$} & \multirow{2}{*}{$\begin{array}{l}\text { Cryptococcus } \\
\text { neoformans }\end{array}$} & \multirow{2}{*}{2} & Female & 66 & $\begin{array}{l}\text { Asthma and } \\
\text { rhinosinusitis }\end{array}$ & $\begin{array}{l}\text { High dose of } \\
\text { inhaled } \\
\text { steroid }\end{array}$ & $\begin{array}{l}\text { Erythematous } \\
\text { and thickened } \\
\text { right true vocal } \\
\text { cord }\end{array}$ & Chronic hoarseness & $\begin{array}{l}\text { Fluconazole } \\
200 \text { mg twice } \\
\text { daily and } \\
\text { reduction of } \\
\text { steroid dose }\end{array}$ & $\begin{array}{l}\text { Complete } \\
\text { resolution } \\
\text { after } 6 \text { months } \\
\text { of treatment }\end{array}$ \\
\hline & & & Female & 69 & Asthma & $\begin{array}{l}\text { Prednisone } \\
\text { short course } \\
\text { and high dose } \\
\text { of inhaled } \\
\text { steroid }\end{array}$ & $\begin{array}{l}\text { Inflammation of } \\
\text { the right true } \\
\text { vocal cord }\end{array}$ & Chronic hoarseness & $\begin{array}{l}\text { Fluconazole } \\
200 \text { mg twice } \\
\text { daily and } \\
\text { reduction of } \\
\text { steroid dose }\end{array}$ & $\begin{array}{l}\text { Complete } \\
\text { resolution } \\
\text { after } 8 \text { months } \\
\text { of treatment }\end{array}$ \\
\hline $\begin{array}{l}\text { Present } \\
\text { case }\end{array}$ & $\begin{array}{l}\text { Cryptococcus } \\
\text { neoformans }\end{array}$ & 1 & Male & 70 & COPD & $\begin{array}{l}\text { Inhaled } \\
\text { steroid and } \\
\text { oral } \\
\text { prednisone }\end{array}$ & $\begin{array}{l}\text { Polypoid } \\
\text { sessile lesion }\end{array}$ & Chronic hoarseness & $\begin{array}{l}\text { Tapered off } \\
\text { prednisone and } \\
\text { inhaled steroid }\end{array}$ & \\
\hline
\end{tabular}

Figure 1 - 760

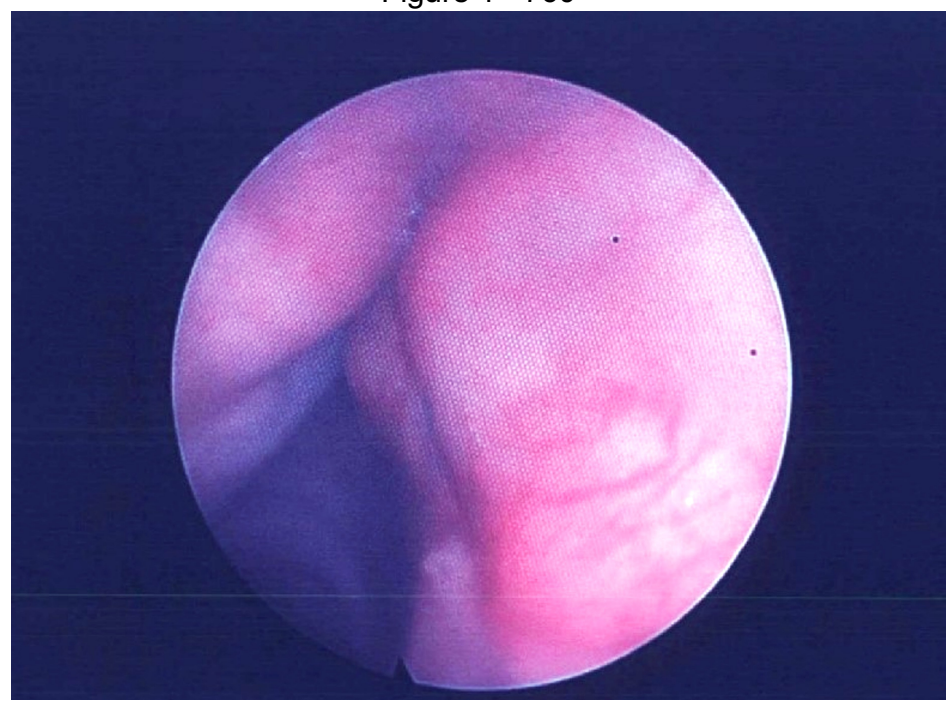

Figure $2-760$

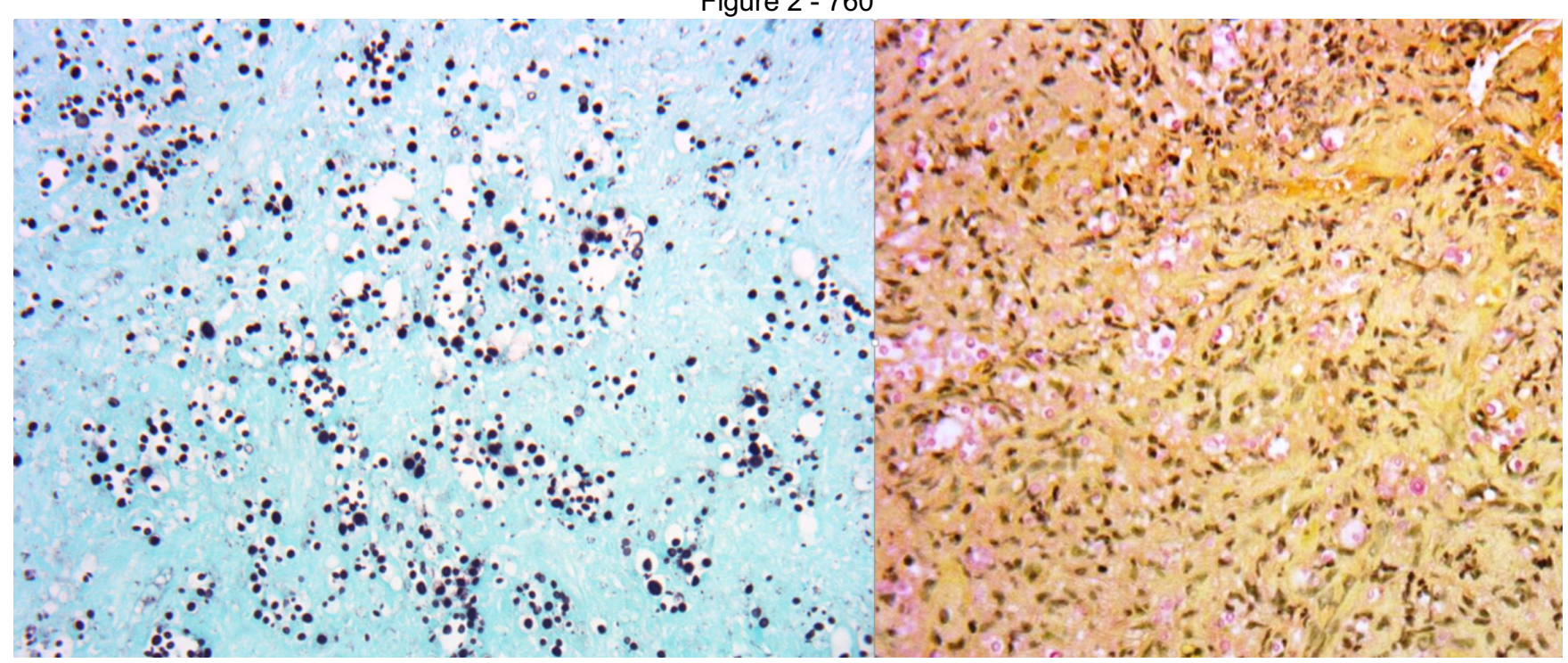

Conclusions: Our literature review, including the current case, revealed that isolated laryngeal infection by Cryptococcus neoformans shows no gender predominance, median age at diagnosis is 69 years old, patients have a past medical history of asthma or COPD in $66 \%$ of cases (14/21), white patches or plaques and erythema are the most common laryngoscopic findings (38\%), 100\% of patients had complete recovery after a variable period 
of oral antifungal therapy. This study highlights an important differential diagnosis in immunocompetent patients who are in chronic use of inhaled steroids.

\section{Evaluation of SARS-CoV-2 Nucleocapsid Immunohistochemistry as a Panfungal Screening Assay \\ Kara Gawelek ${ }^{1}$, Robert Padera ${ }^{1}$, Alvaro Laga², Isaac Solomon ${ }^{1}$ \\ ${ }^{1}$ Brigham and Women's Hospital, Boston, MA, ${ }^{2}$ Brigham and Women's Hospital, Harvard Medical School, Boston, MA}

Disclosures: Kara Gawelek: None; Robert Padera: None; Alvaro Laga: None; Isaac Solomon: None

Background: Immunohistochemistry $(\mathrm{IHC})$ is an important ancillary testing method used diagnostically and in the research setting. Our efforts to investigate the histopathologic manifestations of COVID-19 have employed a severe acute respiratory syndrome coronavirus 2 (SARS-CoV-2) IHC stain to localize virus in patient tissues. In a subset of COVID-19 autopsy cases, we observed robust off-target staining of fungal hyphae and yeast (Figure 1). While fungal elements are typically straightforward to identify in anatomic pathology specimens using H\&E, Periodic acidSchiff, or methenamine silver stains, equivocal structures are occasionally encountered, and there are no widely used fungal IHC stains. Based on these observations, we systematically investigated SARS-CoV-2 IHC staining in a wide range of fungal species to determine the generalizability and frequency of this off-target staining, and to assess for possible utility as a broad spectrum fungal staining assay to assist in cases with equivocal histochemical staining.

Design: Representative anatomic pathology cases with fungal organisms were selected, representing sixteen different fungal genera, of which 15/22 (68\%) were confirmed through culture or sequencing. IHC was performed on formalin-fixed paraffin-embedded tissue sections using a rabbit polyclonal antibody derived from SARS-CoV nucleocapsid protein (NB100-56576; Novus Biologicals) with a DAB brown reaction product. In addition, off-target staining of 26 frequently utilized cell lineage and viral IHC markers was also examined in cases with Aspergillus sp. and Histoplasma sp.

Results: SARS-CoV-2 staining was present in 4/22 (18\%) cases, including Candida spp.

$(n=2)$, Coccidioides sp. $(n=1)$, and one polymicrobial case with Fusarium sp. IHC negative fungal elements were identified by hematoxylin counter staining in the remaining cases. Other examined IHC markers showed moderate multifocal positivity for CK7 and CEA in Aspergillus sp., and claudin-4 in Candida sp., while the 23 other markers were negative for both species.

Figure 1 - 761
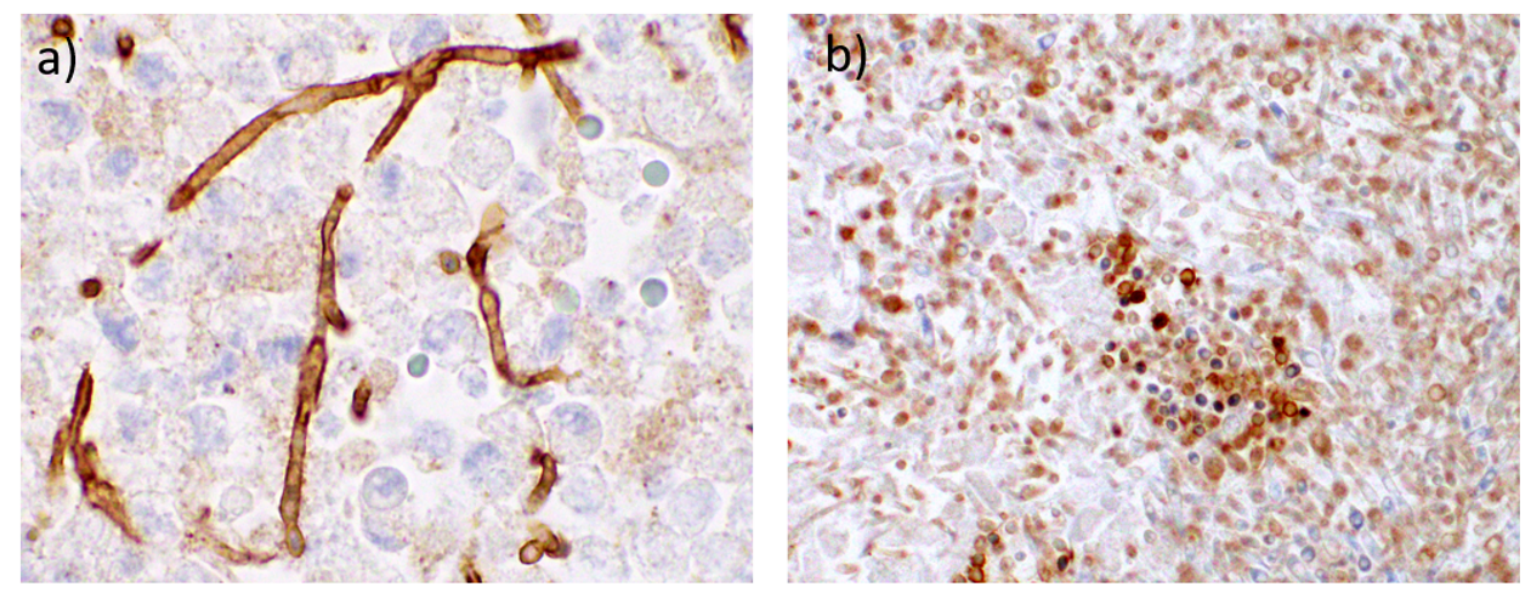

Figure 1. SARS-CoV-2 IHC highlighting a) fungal hyphae present as post-mortem colonization in a COVID19 autopsy case and $b$ ) yeast forms in a non-COVID-19 surgical case. 
Conclusions: SARS-CoV-2 IHC staining should be carefully reviewed in cases of unconfirmed COVID-19 to avoid mis-diagnosis of fungus as sloughed virally infected epithelial cells. Although fungus may occasionally stain with SARS-CoV-2 IHC or the other commonly used IHC markers tested in this study, this phenomenon is inconsistent, limiting the utility for any of these antibodies to serve as broad spectrum fungal markers.

\section{Temporary Androgen Deprivation As a Simple Effective Treatment for Men with COVID-19: Preclinical Evidence \\ RongRong Huang ${ }^{1}$, Andrew Goldstein ${ }^{1}$, Liying Zhang², Takao Hashimoto ${ }^{3}$, Matthew Rettig ${ }^{3}$, Weibo $\mathrm{Yu}^{2}$, Jianyu Rao², Huihui $\mathrm{Ye}^{2}$ \\ ${ }^{1}$ David Geffen School of Medicine at UCLA, Los Angeles, CA, ${ }^{2}$ University of California, Los Angeles, Los Angeles, CA, ${ }^{3}$ UCLA Medical Center and David Geffen School of Medicine, Los Angeles, CA}

Disclosures: RongRong Huang: None; Andrew Goldstein: None; Liying Zhang: Stock Ownership, Shanghai Genome Center; Employee, Shanghai Genome Center; Takao Hashimoto: None; Matthew Rettig: Speaker, Bayer; Speaker, Janssen; Consultant, Amgen; Consultant, Ambryx; Grant or Research Support, Novartis; Weibo Yu: None; Jianyu Rao: None; Huihui Ye: None

Background: The morbidity and mortality of COVID19 in men are reported higher than women. The entry of SARS-CoV-2 virus into host cells is mediated by the interaction between viral spike (S) protein and two host cell surface molecules: receptor ACE2 and primer TMPRSS2. Furin, another protease, may also be involved in $S$ protein priming. TMPRSS2 is known to be transcriptionally upregulated by androgen in prostate cancer (PCa). A study from Italy showed that PCa patients on Androgen Deprivation Therapy (ADT) had a significantly lower COVID-19 incidence compared to PCa patients not on ADT. Based on those evidence, a phase II randomized multi-institutional "HITCH" clinical trial, using degarelix to rapidly suppress androgen, is currently open for hospitalized male COVID-19 patients. In this study, we aim to assess the role of androgen in regulating TMPRSS2, ACE2, and furin in respiratory epithelium, and to establish correlative tissue biomarker assays for the HITCH trial.

Design: Immunohistochemistries (IHC) for AR, TMPRSS2, ACE2, and furin were performed on tissue sections of normal human and murine upper and lower respiratory tract tissue. IHC was also performed on cell blocks prepared from nasopharyngeal (NP) swabs of 12 virus-negative individuals and $4 \mathrm{HITCH}$ trial patients. Male mice were surgically castrated ( $\mathrm{N}=6$, all young mice) or treated with ADT drug enzalutamide $(\mathrm{N}=6,3$ young and 3 old each). Treated mice and paired untreated control mice were sacrificed. Respiratory tract and prostate tissue were harvested for $\mathrm{IHC}$ evaluation and western blot.

Results: Co-expression of AR, TMPRSS2, ACE2, and furin were detected by IHC in male human and murine respiratory epithelium, mainly in sinonsal, bronchial, and bronchiolar mucosa (Figure 1). AR shows weak expression in the respiratory epithelium and moderate expression in salivary glands and lacrimal glands. In females, respiratory epithelium is negative for AR and is positive for TMPRSS2, ACE2, and furin. Expression of AR, TMPRSS2, ACE2, and furin were also detected in respiratory epithelial cells prepared from NP swab specimens. In mice, castration was consistently associated with a marked reduction of AR and TMPRSS2 expression in lacrimal and salivary glands, and a moderate reduction of AR and TMPRSS2 expression in sinonasal epithelium (Figure 2). Reduction of ACE2 and furin was also observed in sinonasal epithelium after castration. Enzalutamide treatment was associated with a mild reduction in ACE2, TMRPSS2, and furin expression in sinonasal epithelium. 
Figure 1 - 762

Fig 1. Co-expression of AR (blue chromogen) and TMPRSS2 (red chromogen) in human respiratory epithelium

(A. Nasosinus; B. Bronchiole)
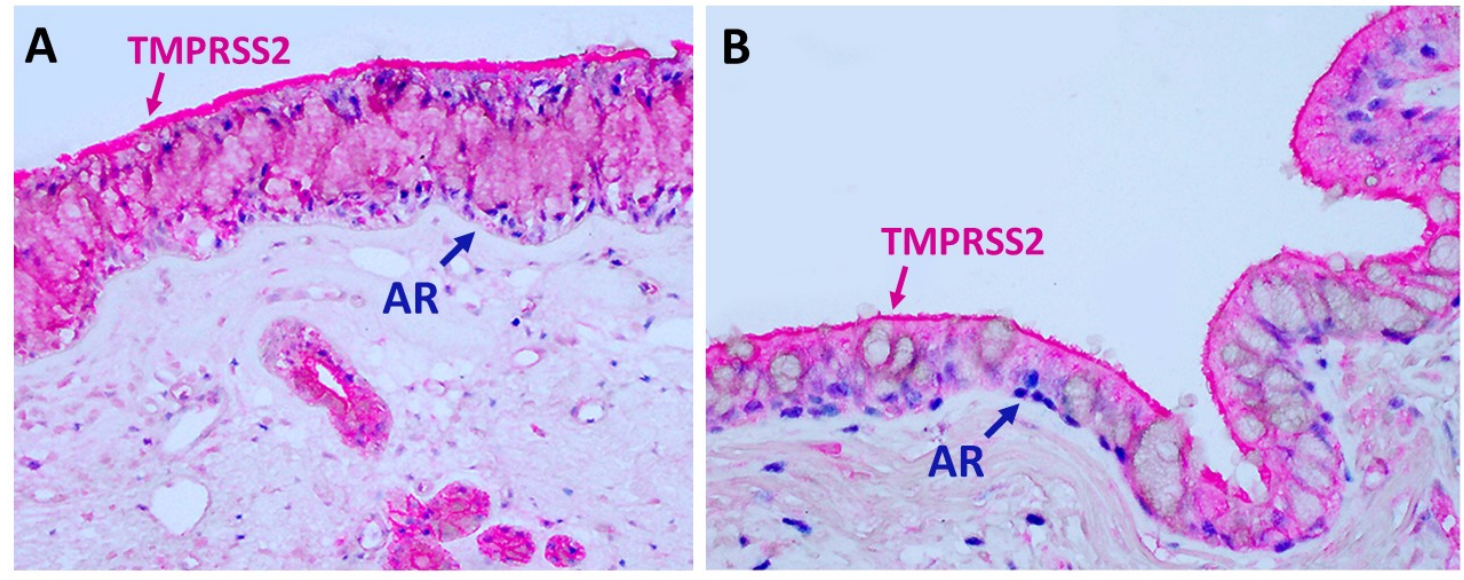

Figure 2 - 762

Fig 2. TMPRSS2 expression in nasal sinus in control and castrated mouse
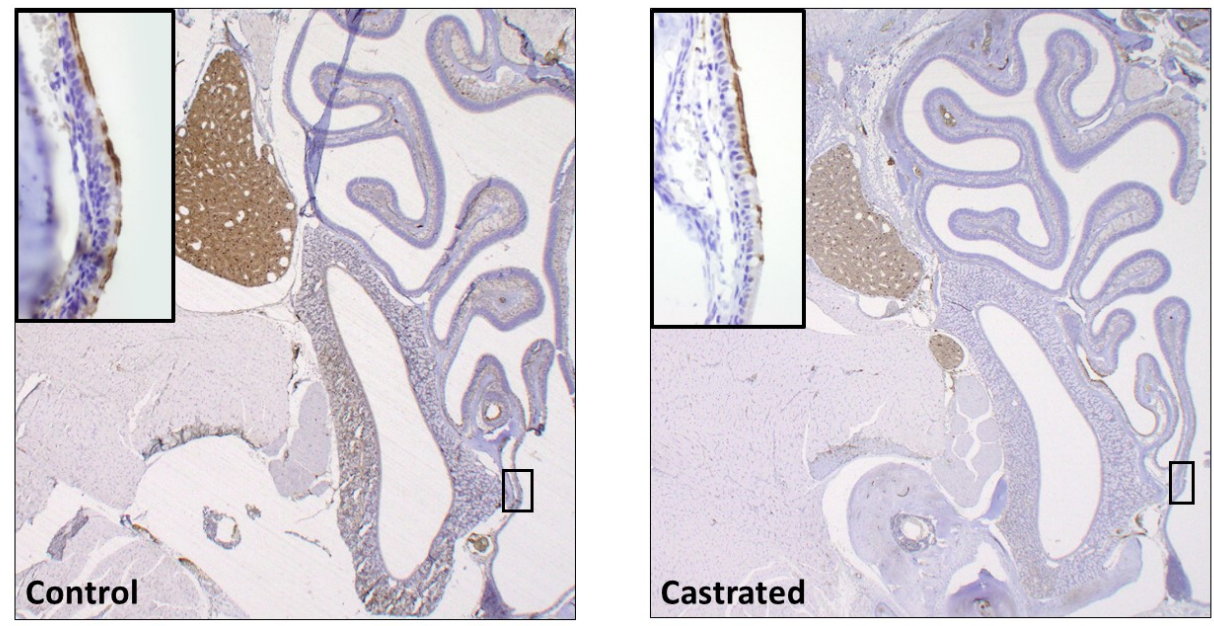

Conclusions: Androgen upregulates expression of TMPRSS2, ACE2, and furin in upper respiratory epithelium in men. Our results provided preclinical evidence to explore the utility of ADT in treating men with COVID-19. The effectiveness of ADT in treating male COVID-19 patients will be tested in the HITCH trial and the biomarker correlates study.

763 Recovery from COVID19 is Associated With An Increase In CD3+, CD4+ and CD8+ T-cells During The Course of Disease

Shafinaz Hussein ${ }^{1}$, Matthew Croken², Siraj El Jamal' ${ }^{2}$, Pallavi Khattar ${ }^{2}$, Francine Dembitzer ${ }^{2}$

${ }^{1}$ Mount Sinai Hospital, New York, NY, ${ }^{2}$ Icahn School of Medicine at Mount Sinai, New York, NY

Disclosures: Shafinaz Hussein: None; Matthew Croken: None; Siraj El Jamal: None; Pallavi Khattar: None;

Francine Dembitzer: None 
Background: The COVID19 pandemic is caused by the novel coronavirus, SARS-CoV-2 (SARS). The majority of individuals with COVID19 are asymptomatic or experience mild disease, however, a subset of patients develop serious respiratory illness. Lymphopenia, primarily affecting T-cells, is a characteristic hematologic finding associated with severe disease. Here, we characterize the changes in T-, B-, and NK-cell subsets during the disease course to determine if any have predictive value.

Design: The pathology database was utilized to identify hospitalized patients $>18$ years of age with SARS infection determined by PCR testing of nasal swab. Peripheral blood samples were analyzed for T-, B- and NK-cell subsets using Beckman Coulter AQUIOS Flow Cytometry System. The antibody panels were CD45/CD4/CD8/CD3 and CD45/CD16+56/CD19/CD3. Lymphocyte subset analyses were performed every 2-5 days until SARS PCR negativity, hospital discharge, or death. Disease severity was defined as follows: mild disease: SpO2>94\% AND no pneumonia on imaging; moderate disease: SpO2<94\% OR pneumonia on imaging; severe disease: high flow nasal cannula, non-rebreather mask, BIPAP or mechanical ventilation support. Complete blood counts with differential, IL6 and IL8 levels, and ABO/Rh blood type were recorded. Linear regression analysis was performed for each laboratory metric.

Results: 33 hospitalized patients (17 males, 16 females, age range 34-93 years, median 68 years) were included in the study. 7 patients were asymptomatic or had mild disease, 13 had moderate disease, and 13 had severe disease. 24 patients recovered, and 9 patients died. There were no readmissions for COVID19. The median absolute CD3 level ranged from 496-1509 count/uL in asymptomatic/mild patients; 291-1284 count/uL in patients with moderate disease and 67-816 count/uL in patients with severe disease. Patients who recovered had an increase in absolute CD3+, CD4+, and CD8+ counts during the course of hospitalization. Absolute B- and NK-cells trended upwards in both survivors and non-survivors, with no difference in median slope in either group. There was a downward trend in IL6 and IL8 levels in surviving patients.

\begin{tabular}{|c|c|c|c|c|c|c|c|}
\hline Disease status & $\begin{array}{l}\text { Male:female; } \\
\text { age range }\end{array}$ & $\begin{array}{l}\text { Blood } \\
\text { type }\end{array}$ & $\begin{array}{l}\text { Median } \\
\text { absolute } \\
\text { CD3 range } \\
\text { counts/uL }\end{array}$ & $\begin{array}{l}\text { Median } \\
\text { absolute } \\
\text { CD4 range } \\
\text { counts/uL }\end{array}$ & $\begin{array}{l}\text { Median } \\
\text { absolute } \\
\text { CD8 range } \\
\text { counts /uL }\end{array}$ & $\begin{array}{l}\text { Median } \\
\text { absolute B } \\
\text { cell range } \\
\text { counts/uL }\end{array}$ & $\begin{array}{l}\text { Median } \\
\text { absolute } \\
\text { NK cell } \\
\text { range } \\
\text { counts/uL }\end{array}$ \\
\hline $\begin{array}{l}\text { Mild/asymptomatic } \\
\mathrm{N}=7\end{array}$ & $\begin{array}{l}2 \mathrm{M}: 5 \mathrm{~F} ; 34-89 \\
\text { years }\end{array}$ & $\begin{array}{l}5 \mathrm{O}- \\
\text { type } \\
2 \mathrm{~A}- \\
\text { type } \\
6 \mathrm{Rh}+\end{array}$ & $496.5-1509$ & $312-804$ & $166.5-692$ & $66.5-321.5$ & $109-404.5$ \\
\hline Moderate, $n=13$ & $\begin{array}{l}5 \mathrm{M}: 8 \mathrm{~F} ; 39-93 \\
\text { years }\end{array}$ & $\begin{array}{l}6 \mathrm{O}- \\
\text { type } \\
3 \mathrm{~B}- \\
\text { type } \\
2 \mathrm{~A}- \\
\text { type } \\
1 \mathrm{AB}- \\
\text { type } \\
9 \mathrm{Rh}+\end{array}$ & $291-1284.5$ & $64-1041.5$ & $102.5-424.5$ & $2-1254$ & $28.5-307.5$ \\
\hline $\begin{array}{l}\text { Severe, } \\
n=13\end{array}$ & $\begin{array}{l}\text { 10M:3F; 38- } \\
83 \text { years }\end{array}$ & $\begin{array}{l}5 \mathrm{O}- \\
\text { type } \\
4 \mathrm{~B}- \\
\text { type } \\
4 \mathrm{~A}- \\
\text { type } \\
13 \\
\mathrm{Rh}+\end{array}$ & $67-816.5$ & $51-514$ & $15-366$ & $0-494.5$ & $23-310$ \\
\hline
\end{tabular}

Conclusions: Recovery from COVID19 is associated with an increase in absolute CD3+ T-cells. Both CD4+ and CD8+ T-cell subsets increased over time in survivors. Lymphocyte subset analysis and increasing CD3/CD4/CD8 T-cells during disease course may be useful predictors in COVID19 infection. 


\section{Quality Control Practice for SARS-CoV-2 PCR Acid Detection: An Additional Quality Control Measure}

Lester Layfield ${ }^{1}$, Douglas Miller ${ }^{1}$, Simone Camp ${ }^{1}$, Kelly Bowers ${ }^{1}$

${ }^{1}$ University of Missouri, Columbia, MO

\section{Disclosures: Lester Layfield: None; Douglas Miller: None}

Background: Testing for SARS-CoV-2 RNA is recommended for those symptomatic from/or exposed to the virus. Most laboratories use polymerase chain reaction (PCR) assays. Published recommendations for quality control (QC) measures mostly rely on use of known positive and negative controls which ensure the adequacy of the extraction and PCR steps but do not measure other components of testing such as specimen contamination, technologist performance or other methodologic issues.

Design: Following our laboratory's detection of a small number of false positive COVID-19 PCR tests in asymptomatic individuals, all samples from asymptomatic unexposed persons with SARS-CoV-2 positive tests were retested to confirm the initial result. When the second test was negative a third test was performed and a rootcause analysis of the error performed. RNA extraction and PCR were performed using the Thermo Fisher (Waltham, MA) or Siemens (Munich, Germany) systems.

Results: Approximately 21,000 COVID tests were performed in an 8-week period. During this period, 6,782 specimens were from asymptomatic persons of which 155 were positive. Replicate testing revealed $30(19 \%)$ of these positive tests to be false positive results. Review of cycle threshold curves, locations of specimens on test plates and technologists' records revealed contamination and false positive sample located near a sample with a high viral load were the most common causes of erroneous results.

Conclusions: Use of only known positive and negative samples appears insufficient for adequate quality control. Focused retesting appears to be a better metric to detect contamination, carry over and technologist error. We have begun a QC program in which all positive samples from asymptomatic unexposed persons, positive samples near high viral load specimens, and $1 \%$ of negative samples from exposed symptomatic patients are retested to monitor quality of technologist performance and validity of test results.

\section{The Diagnostic and Prognostic Roles of EBER for Patients With HIV-Associated} Aggressive Non-Hodgkin Lymphomas In The Era of HAART

Brenda Mai ${ }^{1}$, Wei Wang ${ }^{2}$, Wen Shuai ${ }^{2}$, Xiaohong Iris Wang ${ }^{3}$, Lei Chen ${ }^{4}$, Hilary Y Ma², Md Amer Wahed ${ }^{1}$, Shimin $\mathrm{Hu}^{2}$, Nghia Nguyen ${ }^{1}$, Zhihong $\mathrm{Hu}^{1}$

${ }^{1}$ The University of Texas Health Science Center at Houston, Houston, TX, ${ }^{2}$ The University of Texas MD Anderson Cancer Center, Houston, TX, ${ }^{3}$ The University of Texas Health Science Center at Houston McGovern Medical School, Houston, TX, ${ }^{4}$ The University of Texas at Houston, Houston, TX

Disclosures: Brenda Mai: None; Wei Wang: None; Wen Shuai: None; Xiaohong Iris Wang: None; Lei Chen: None; Hilary Y Ma: None; Md Amer Wahed: None; Shimin Hu: None; Nghia Nguyen: None; Zhihong Hu: None

Background: HIV infection remains an increased risk to develop lymphomas in the era of HAART therapy. HIVassociated NHLs are predominantly aggressive large B cell lymphomas with a high incidence of concurrent EBV infection. However, the prognostic role of EBV infection is not well defined in this group of patients.

Design: We retrospectively reviewed the HIV+ patients with aggressive non-Hodgkin lymphomas during the interval of 2008-2019 at our institution. One subset of cases were re-classified following the 2017 revised World Health Organization criteria. Patient's clinical information and prognosis were analyzed.

Results: Our current study includes 101 patients with HIV-associated NHLs in the recent 12 years, composed of 14 women and 87 men with a median age of 45 years (range, 20-67) at the diagnosis of lymphoma. In the era of HAART therapy, EBER was positive in 34/67 cases examined and EBV-LMP1 in 5/16 cases, with $1 / 2$ EBV-LMP1 positive in EBER+. Diffuse large B cell lymphomas (DLBCL) remained the most frequent type of aggressive NHLs, in $44(44 \%)$ patients, with EBER positive in 7/19 (37\%) and EBV-LMP1 3/9 (33\%) cases. Plasmablastic lymphoma 
(PBL) was the second most frequent, in $22(22 \%)$ NHL patients, with EBER positive in 20/20 (100\%) and EBV-LMP in $1 / 3(33 \%)$ cases examined. Eighteen patients had high grade B cell lymphomas (HGBCL) with 15 NOS and 3 MYC/BCL6 rearrangements; EBER positive in 3/7 cases examined. $10(10 \%)$ patients had diagnosis of Burkitt lymphoma (BL), with EBER positive in 2/4 and EBV-LMP1 1/3 (33\%) cases. $5(5 \%)$ patients had diagnosis of primary effusion lymphoma (PEL) with HHV8 positive in $5 / 5(100 \%)$ and EBER positive in $2 / 3(67 \%)$ cases. $3 / 5$ $(60 \%)$ PEL patients had preceding/concurrent Kaposi's sarcoma. Two patients (2\%) were diagnosed with B-acute lymphoblastic leukemia (B-ALL), none of them were positive for EBER. With a median follow up of 10 months (range, $<1.0-119.6$ ), patients with NHLs had a median OS of 65 months. Patients with EBV+ NHLs had no different survival than EBV- NHLs $(p=0.86)$. However, patients with EBV+ HGBCL had an inferior survival from EBV-negative HGBCL $(p=0.02)$.

Conclusions: EBV infection is high in patients with HIV-associated NHLs. The utilization of EBER are not only a diagnostic marker for plasmablastic lymphoma and primary effusion lymphoma, but also a prognostic marker for high grade B cell lymphoma. We would suggest the utilization of EBER in the diagnosis and prognostic evaluation for aggressive HIV-associated NHLs.

\section{Histologic, Direct Immunofluorescence, and ISH Findings in a Case Series of 3 Living COVID-19 Patients and Evidence of Prolonged Persistent Viral Replication Romana Mayer ${ }^{1}$, Allen Burke ${ }^{2}$, Cheng-Ying Ho ${ }^{1}$, Guanghua Wang ${ }^{3}$, Jennifer Holler ${ }^{4}$, Shimin Zhang ${ }^{5}$ ${ }^{1}$ University of Maryland Medical Center, Baltimore, MD, ${ }^{2}$ University of Maryland Medical School of Medicine, Baltimore, MD, ${ }^{3}$ The Joint Pathology Center, Bethesda, MD, ${ }^{4}$ University of Maryland School of Medicine, Baltimore, MD, ${ }^{5}$ The Joint Pathology Center, Silver Spring, MD}

Disclosures: Romana Mayer: None; Allen Burke: None; Cheng-Ying Ho: None; Guanghua Wang: None; Jennifer Holler: None; Shimin Zhang: None

Background: Previously reported histopathologic and tissue viral studies have been performed on autopsy samples. Little is known about the progression of COVID-19 pneumonia within living patients and how histology, viral presence, and viral replication are affected as the disease advances.

Design: Patients who had COVID-19 positive pneumonia and underwent lung biopsies from March through June 2020 were selected for a total of 3 patients. Biopsies were taken 1 day, 19 days, and 37 days after initial COVID positive diagnosis between the 3 patients. Direct immunofluorescence (DIF) probes (GeneTex) against the SARSCoV-2 RNA spike protein (S2 subunit) and RNA in-situ hybridization (RNAscope) probes (SARS-CoV-2 viral spike gene negative strand probe to detect viral genomic RNA and positive strand spike gene probe to detect minus-strand viral RNA for viral replication status) were applied to paraffin sections. RNAscope assay was validated comparing known positive cases with semiquantitative Real-time RT PCR for SARS-CoV-2 viral RNA.

Results: The short duration (1 day) biopsy showed mild diffuse interstitial inflammation with uniform reactive pneumocyte hyperplasia without hyaline membranes. The long duration biopsies (19 and 37 days) showed intense interstitial macrophage infiltrates; one of these had concomitant herpes simplex necrotizing pneumonitis superinfection. There were areas of organizing alveolar injury (loose fibrosis) in the 37 day biopsy. Immunofluorescence for SARS-CoV-2 protein was positive in all 3 biopsies in a pneumocyte distribution in scattered foci. Percent positive tissue inversely related to the time from initial diagnosis. RNAscope for both positive and negative strand probes was positive very focally in interstitial cells and cells in the airspaces, in the 37 day biopsy, indicating active viral replication, but negative in the others. A COVID-19 DAD control with diffuse alveolar damage (DAD) showed the greatest positivity with DIF with nearly diffuse pneumocyte staining and was focally positive in RNAscope assay (positive strand viral RNA). 


\begin{tabular}{|c|c|c|c|c|c|c|}
\hline Patient & $\begin{array}{l}\text { Interval } \\
\text { between onset } \\
\text { of symptoms to } \\
\text { biopsy }\end{array}$ & Histologic findings & Clinical Outcome & $\begin{array}{l}\text { DIF (\% area } \\
\text { positive* }^{*}\end{array}$ & $\begin{array}{l}\text { ISH + } \\
\text { Strand }\end{array}$ & $\begin{array}{l}\text { ISH - } \\
\text { Strand }\end{array}$ \\
\hline 37 yo $F$ & 1 day & $\begin{array}{l}\text { Sparse interstitial inflammation with } \\
\text { diffuse pneumocyte reactivity }\end{array}$ & recovery & $60 \%$ & - & - \\
\hline 43 yo $F$ & 19 days & $\begin{array}{l}\text { Interstitial mononuclear cell inflammation } \\
\text { with patchy alveolar injury }\end{array}$ & $\begin{array}{l}\text { Died one week } \\
\text { after biopsy }\end{array}$ & $50 \%$ & - & - \\
\hline 37 yo $\mathrm{M}$ & 37 days & $\begin{array}{l}\text { Interstitial mononuclear cell inflammation } \\
\text { with patchy alveolar injury; concomitant } \\
\text { focal HSV necrotizing pneumonitis }\end{array}$ & $\begin{array}{l}\text { Died two weeks } \\
\text { after biopsy }\end{array}$ & $30 \%$ & + & + \\
\hline $\begin{array}{l}\text { Positive } \\
\text { control }\end{array}$ & Unknown & $\begin{array}{l}\text { COVID-19 Diffuse alveolar damage with } \\
\text { hyaline membranes }\end{array}$ & $\begin{array}{l}\text { Medical } \\
\text { examiner's } \\
\text { autopsy }\end{array}$ & $100 \%$ & + & - \\
\hline $\begin{array}{l}\text { Negative } \\
\text { control }\end{array}$ & $N / A$ & $\begin{array}{l}\text { Normal lung except for areas of aspiration } \\
\text { pneumonia, COVID-19 + patient died of } \\
\text { perforated bowel }\end{array}$ & $\begin{array}{l}\text { Medical } \\
\text { examiner's } \\
\text { autopsy }\end{array}$ & 0 & - & - \\
\hline
\end{tabular}

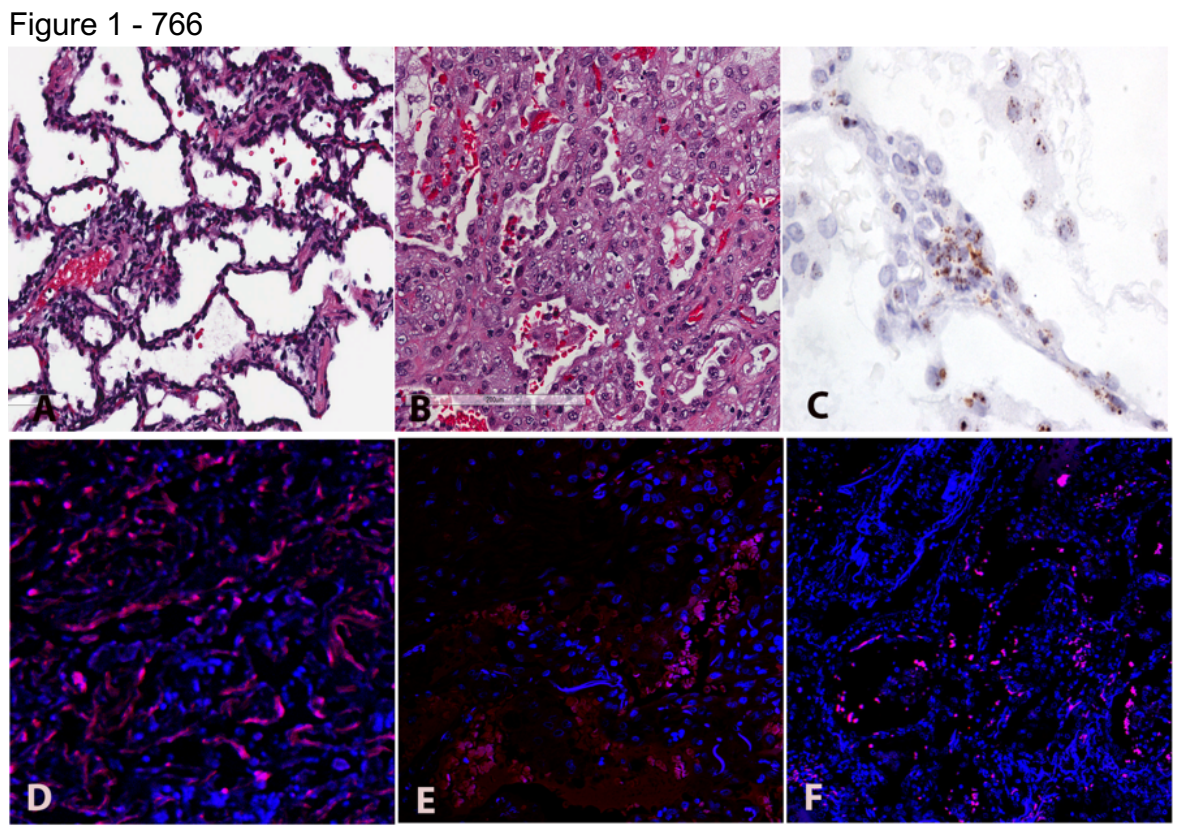

Figure 1. A. H\&E of patient with 1 day interval, B. H\&E of patient with 37 day interval, C. ISH for minus-strand viral RNA to detect replication, D. DIF for patient with 1 day interval, E. DIF for patient with 19 day interval, F. DIF for patient with 37 day interval

Conclusions: COVID-19 pneumonitis in this series of living patients was characterized by an interstitial mononuclear cell infiltrate which increased with time. This finding is in contrast to diffuse alveolar damage seen in patients who die in the acute phase of disease. The presence of ISH minus strand viral RNA and spike protein weeks after infection suggests that viral replication can persist for a long period.

\section{Mucosal Eosinophilic Infiltration May be a Characteristic of Human Intestinal Spirochetosis \\ Sho Ogata ${ }^{1}$, Ken Shimizu², Susumu Tominaga ${ }^{1}$, Susumu Matsukuma ${ }^{1}$ \\ ${ }^{1}$ National Defense Medical College, Tokorozawa, Japan, ${ }^{2} \mathrm{JCHO}$ Saitama Medical Center, Saitama, Japan}

Disclosures: Sho Ogata: None; Ken Shimizu: None; Susumu Tominaga: None; Susumu Matsukuma: None

Background: Human intestinal spirochetosis (HIS) is a bacterial infectious disease of human large intestines, and most HIS cases are asymptomatic or exhibit mild intestinal symptoms. The host reaction to HIS remains unclear. 
Design: We examined HIS-related mucosal inflammatory features histologically. From the archival HIS cases in a single medical center, 24 endoscopically taken specimens from 14 HIS cases (M:F = 10:4; 28-73 yrs) were selected as not containing polypoid or neoplastic lesions. Stromal and intraepithelial neutrophils and eosinophils, and stromal mast cells were counted, and the presence or absence of lymphoid follicles/aggregates was also examined. Association of the above inflammation parameters and spirochetal infection parameters (such as degrees of characteristic fringe distribution, of spirochetal cryptal invasion, and of spirochetal intraepithelial invasion) were also analysed.

Results: Intraepithelial neutrophils were observed in $29.2 \%$, intraepithelial eosinophils in $58.3 \%$, and lymphoid follicles in $50.0 \%$ of the specimens. Maximal stromal neutrophil, eosinophil, and mast cell counts averaged 8.4, 21.5 , and 6.0, respectively, while intraepithelial neutrophils and eosinophils were 0.5 and 1.5 , respectively. Strong correlation between iNeu and iEo $(p<0.001, r=0.81)$, and correlations between iEo and sNeu $(p=$ $0.0012, r=0.62)$ and between iEo and sEo $(p=0.026, r=0.45)$ were observed. Intraepithelial neutrophilic infiltration was influenced by fringe formation $(p<0.05)$ and spirochetal crypt involvement $(p<0.05)$.

Conclusions: HIS was accompanied by inflammatory reactions, including eosinophilia, lymphoid follicles/aggregates, and intraepithelial neutrophils and eosinophils. Among these, mucosal eosinophilic infiltration may be a central indicator and host reaction of HIS.

\section{Galactomannan-Negative Aspergillus Fumigatus Presents with Unusual Morphology in Pediatric Patient with Septic Emboli and Complicated Medical History Kara Roncin ${ }^{1}$, Sree Sarah Cherian² ${ }^{1}$ University Hospitals Cleveland Medical Center, Case Western Reserve University, Lyndhurst, $\mathrm{OH},{ }^{2}$ Case Western Reserve University/University Hospitals Cleveland Medical Center, Cleveland, $\mathrm{OH}$}

Disclosures: Kara Roncin: None; Sree Sarah Cherian: None

Background: Invasive aspergillosis caused by Aspergillus fumigatus has been well documented within the literature, with recent focus on molecular variations that have the potential to change pathogenicity of $A$. fumigatus when exposed to different environmental stressors. The majority of publications devoted to clinical cases of invasive aspergillosis focus on immunocompromised patients.

Design: Here we present the case of a 15-year old female without neutropenia or use of high dose corticosteroids, who presented with fevers, tachypnea, and numerous unprovoked septic thrombi following recent recovery from SARS-CoV-2 infection (COVID-19) without associated thrombotic complications.

Imaging revealed multiple large thrombi involving the right atria, right main pulmonary arteries, and hepatic veins. There was a suspected abscess within the lower lobe of the right lung in addition to diffuse peripheral and right basilar interstitial changes. Lymphadenopathy involving the mediastinum, right paratracheal, and subcarinal lymph nodes was present.

Results: Samples from right atrial thrombi and bronchial alveolar lavage were positive for septate hyphae on fluorescent staining. On solid agar, white, slow- growing fungal colonies appeared within one week of incubation (Figure 1). On microscopic examination with lactophenol cotton blue, the fungus demonstrated septate hyphae, absence of conidia, rare conidiophores with bare vesicles, and numerous structures consistent with terminal and intercalary chlamydospores (Figure 2). Matrix assisted laser desorption ionization-time of flight mass spectrometry (MALDI-TOF MS) performed on the fungal isolate was positive for $A$. fumigatus, which was confirmed via broad range PCR (utilizing a nested ITS primer set).

While Beta-D glucan was positive on serum, the galactomannan immunoenzymatic assay (EIA) was negative on both serum and CSF.

Fungal antibodies for Aspergillus spp and Blastomyces spp were negative, however, a second antibody assay for Aspergillus spp was positive. 
Figure 1 - 768

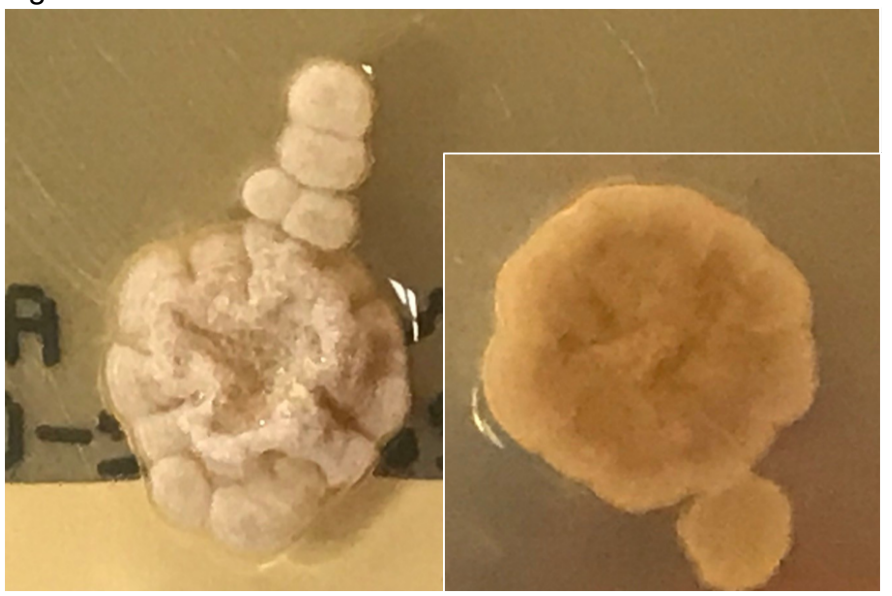

Figure 2 - 768

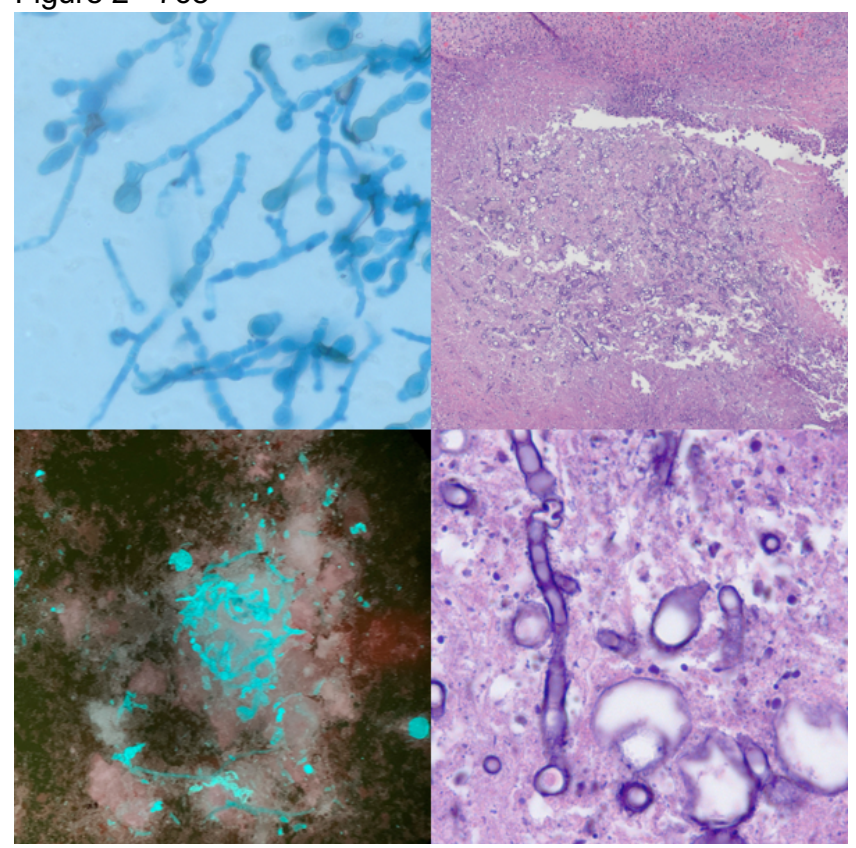

Conclusions: In this patient galactomannan remained negative despite invasive aspergillus infection, and similar cases have been documented, thought to be related to low levels of circulating galactomannan below the limit of detection of the EIA test. The unusual microscopic appearance of the isolate with chlamydospore formation suggests a response to unfavorable conditions, due to which inadequate levels of galactomannan may have been released into the serum for conventional detection.

\section{Atypical/Clonal T-lymphoid Populations in Splenic Parenchyma in Babesia Infection Associated with Splenic Rupture}

Diana Treaba ${ }^{1}$, Mikhail Gorbounov², Lee Cross ${ }^{3}$, Jennifer Mingrino², Fouad Zakka ${ }^{3}$, Stephanie Riviere ${ }^{2}$, Cynthia Jackson ${ }^{4}$, Karren Ferreira ${ }^{3}$, Habibe Kurt ${ }^{5}$, Patrycja Dubielecka-Szczerba ${ }^{5}$, Evgeny Yakirevich ${ }^{4}$ ${ }^{1}$ Brown University Lifespan Academic Medical Center, Providence, RI, ${ }^{2}$ Brown University, Rhode Island Hospital, Providence, RI, ${ }^{3}$ Brown University, Rhode Island Hospital, Lifespan, Providence, Rl, ${ }^{4}$ Rhode Island Hospital, Providence, RI, ${ }^{5}$ Alpert Medical School of Brown University, Providence, RI

Disclosures: Diana Treaba: None; Mikhail Gorbounov: None; Lee Cross: None; Fouad Zakka: None; Stephanie Riviere: None; Karren Ferreira: None; Habibe Kurt: None; Evgeny Yakirevich: None

Background: Discovered by the Romanian microbiologist Dr. Victor Babes in 1885, babesiosis is a worldwide spread zoonosis, endemic in the northeastern and upper midwestern USA regions. Transmitted by tick bite ( $I$. scapularis), the clinical disease can range from asymptomatic, to a mild febrile illness, and in some patients to a severe or even fatal disease. The presentation of babesiosis with splenic rupture has a mechanism still incompletely understood.

Design: We describe three cases of patients infected with Babesia species who presented/developed splenic rupture. The men were 47 and 48 years old respectively, while the woman was 58 years old. Their degree of parasitemia at presentation was $0.11 \%, 0.42 \%$ and $0.37 \%$. They all tested negative for Anaplasma (morphology and PCR) and the 48 year old man had a mildly elevated Lyme reflex (1.13; range 0-0.91), while the others tested negative. All patients presented with splenic rupture and underwent splenectomy. The spleen specimens were submitted for histopathological and immunophenotypical evaluation.

Results: All patients had anemia and thrombocytopenia at presentation (see Table 1). The spleens weighed 256, 382 and $299 \mathrm{~g}$. Histopathologic examination was notable for expanded white pulp containing parenchymal regions with recent hemorrhage, and an increased population of histiocytes in a small subset with hemophagocytosis. The 
white pulp was preserved, had primary and secondary follicles, some with variable degree of apoptosis of their germinal centers. By immunohistochemistry, the red pulp had an increased CD3+, CD56-, CD30-, TdT- T-lymphoid population with partial loss of CD5 and bcl2, with a slightly reversed CD4 to CD8 cell ratio, and in the single case where flow cytometry was performed the CD4 to CD8 cell ratio was 0.6 , and there was detected a subset $(33 \%$ of the T-cells) of CD8+ T-lymphoid cells with partial loss of CD5, and also a subset (20\%) of double negative (CD4 and CD8) T-lymphoid cells also with partial loss of CD5. The B-lymphoid cells were polytypic. Molecular studies were performed only in two cases, and detected only in one case minor T-cell receptor beta and gamma T-cell receptor gamma gene rearrangements. Of interest, two cases had also a few EBER positive nuclei suggestive of possible associated co-infection.

\begin{tabular}{|c|c|c|c|c|c|c|c|c|}
\hline Age & Sex & $\begin{array}{l}\text { Degree of } \\
\text { parasitemia }\end{array}$ & $\begin{array}{l}\mathrm{Hgb} \\
\mathrm{g} / \mathrm{dL}\end{array}$ & $\begin{array}{l}\text { WBC } \\
\times 10^{9} / \mathrm{L}\end{array}$ & $\begin{array}{l}\text { PIts } \\
\times 10^{9} / \mathrm{L}\end{array}$ & $\begin{array}{l}\text { Spleen } \\
\text { grams }\end{array}$ & $\begin{array}{l}\text { PCR } \\
\end{array}$ & EBER \\
\hline 47 & $\mathrm{M}$ & $0.11 \%$ & 10.1 & 10.9 & 78 & 256 & $\begin{array}{l}\text { Minor } \\
\text { clonal } T R B \text { and TRG rearrangements }\end{array}$ & Negative \\
\hline 48 & $\bar{M}$ & $0.42 \%$ & 8.6 & 2.7 & 59 & 382 & $\begin{array}{l}\text { Negative } \\
\text { for TRB, TRG and } I G H \text { rearrangements }\end{array}$ & $\begin{array}{l}\text { A small } \\
\text { loose } \\
\text { aggregate } \\
\text { of positive } \\
\text { cells }\end{array}$ \\
\hline 58 & $\mathrm{~F}$ & $0.37 \%$ & 9.7 & 3.2 & 91 & 299 & Not done & $\begin{array}{l}\text { Rare } \\
\text { positive } \\
\text { cells }\end{array}$ \\
\hline
\end{tabular}

Conclusions: While atypical/clonal T-lymphoid populations have been reported in infectious processes, this is the first report identifying the presence of atypical/clonal T-lymphoid population(s) in splenic parenchyma of patients with Babesia infection with associated splenic rupture.

\section{SARS-CoV-2 Related Biomarker Investigation: Lessons from a Single Institution Autopsy Series}

Xiaoming (Mindy) Wang ${ }^{1}$, Rahul Mannan ${ }^{2}$, Yuanuan Qiao ${ }^{1}$, Eman Abdulfatah ${ }^{2}$, Allecia Wilson ${ }^{1}$, Jeffrey Jentzen $^{1}$, Lisa McMurry ${ }^{3}$, Carol Farver ${ }^{4}$, Jeffrey Myers ${ }^{5}$, Liron Pantanowitz ${ }^{1}$, Sylvia Zelenka-Wang ${ }^{3}$, Yuping Zhang $^{3}$, Xuhong $\mathrm{Cao}^{1}$, Arul Chinnaiyan ${ }^{1}$, Rohit Mehra ${ }^{1}$

${ }^{1}$ University of Michigan, Ann Arbor, MI, ${ }^{2}$ Michigan Medicine, University of Michigan, Ann Arbor, MI, ${ }^{3}$ Michigan Center for Translational Pathology, Ann Arbor, MI, ${ }^{4}$ University of Michigan School of Medicine, Ann Arbor, MI, ${ }^{5}$ Michigan Medicine, Ann Arbor, MI

Disclosures: Xiaoming (Mindy) Wang: None; Rahul Mannan: None; Eman Abdulfatah: None; Jeffrey Jentzen: None; Lisa McMurry: None; Carol Farver: None; Jeffrey Myers: None; Liron Pantanowitz: None; Sylvia ZelenkaWang: None; Yuping Zhang: None; Xuhong Cao: None; Arul Chinnaiyan: None; Rohit Mehra: None

Background: COVID-19 was declared a pandemic in March 2020 by the World Health Organization. As of 14 October 2020, more than 38.3 million cases have been confirmed, with more than 1.08 million deaths. COVID-19 affects multi-organ systems with the highest impact noted in the respiratory, cardiovascular, gastrointestinal, neurological, renal and immune organs in humans. COVID-19 is caused by severe acute respiratory syndrome coronavirus 2 (SARS-CoV-2), a positive-sense single-stranded RNA virus. This virus enters host cells through attachment of the viral spike (S) glycoproteins to the host transmembrane receptor protein, the angiotensinconverting enzyme 2 (ACE2), followed by spike protein cleavage and activation by cell surface transmembrane protease serine 2 (TMPRSS2). Knowledge about the spectrum of SARS-CoV-2 infection, ACE2 and TMPRSS2 expression in various human organs would benefit our understanding of the infection mechanism and potential future therapies.

Design: In this study, we performed pathology and biomarker characterization in 6 COVID-19 autopsy cases with interrogation of several organ systems affected by SARS-CoV-2. Specifically, we utilized an RNA in situ hybridization (RNA-ISH) approach to survey the localization of SARS-CoV-2 virus with a probe against the S gene (V-nCoV2019-S), virus replication with a probe against the anti-sense of the S gene (V-nCoV2019-S-sense), 
host entry receptor ACE2, and priming protease TMPRSS2, in postmortem human tissues. The presence of SARS-CoV-2 virus was correlated with the expression of host entry machinery in the affected organs.

Results: V-nCoV2019-S stain was visualized as individual brown punctate dots or clusters. SARS-CoV-2 virus were detected in the respiratory tract (trachea, bronchus, lung parenchyma), colon, liver, thyroid, lymph node, kidney and prostate. Viral signals were not detected in heart, adrenal, pancreas, stomach, small intestine, or uterus in this cohort. By V-nCoV2019-S-sense probe RNA-ISH evaluation, we detected viral replication as brown signal clusters in all organ systems where virus was detected, except lymph node. Viral presence was heterogeneous among tissue sections sampled from different lobes of the lung and different areas of non-pulmonary tissues. The density of SARS-CoV-2 virus was variable among different organs and cases, with higher abundance in the respiratory tract. The highest virus abundance was observed in a patient who was immunocompromised secondary to renal transplant for end-stage diabetic nephropathy. ACE2 and TMPRSS2 were detected in all organ systems where virus was detected, except colon; ACE2 was also detected in the heart and uterus.

Table 1. Clinical characteristics of the 6 COVID-19 autopsy cases.

\begin{tabular}{|l|l|l|l|l|l|}
\hline $\begin{array}{l}\text { Case } \\
\text { ID }\end{array}$ & Age & Gender & Race & Histopathology and final diagnosis & Other significant conditions \\
\hline 1 & 53 & M & Caucasian & $\begin{array}{l}\text { Diffuse alveolar damage, acute, } \\
\text { exudative phase }\end{array}$ & Type A aortic dissection-operated \\
\hline 2 & 46 & M & $\begin{array}{l}\text { African } \\
\text { American }\end{array}$ & $\begin{array}{l}\text { Adult respiratory distress } \\
\text { syndrome, proliferative diffuse } \\
\text { alveolar damage, and acute renal } \\
\text { failure }\end{array}$ & $\begin{array}{l}\text { Cardiomegaly: myofibrillary } \\
\text { hypertrophy; Hpatomegaly: mild to } \\
\text { moderate steatosis; hypertension, } \\
\text { diabetes and obesity }\end{array}$ \\
\hline 3 & 79 & F & Caucasian & Adult respiratory distress syndrome & $\begin{array}{l}\text { Ischemic bowel disease, } \\
\text { hypotension: caridomegaly, } \\
\text { myofibrillary hypertrophy, end stage } \\
\text { kidneys status post-transplant }\end{array}$ \\
\hline 4 & 37 & M & Caucasian & $\begin{array}{l}\text { Diffuse alveolar damage, fibrinous } \\
\text { pneumonia }\end{array}$ & $\begin{array}{l}\text { Asthma, hemorrhage, edema and } \\
\text { mucus plugging, hemopericardium, } \\
\text { pleural effusions and ascites }\end{array}$ \\
\hline 5 & 80 & M & $\begin{array}{l}\text { African } \\
\text { American }\end{array}$ & $\begin{array}{l}\text { Diffuse alveolar damage, acute and } \\
\text { organizing bronchopneumonia, } \\
\text { hemorrhage and edema }\end{array}$ & $\begin{array}{l}\text { Coronary artery disease, } \\
\text { hypertension, type 2 diabetes } \\
\text { mellitus }\end{array}$ \\
\hline 6 & 66 & M & Caucasian & Under Review & Under Review \\
\hline
\end{tabular}

Conclusions: SARS-CoV-2 virus was detected in postmortem human respiratory tract, gastrointestinal, genitourinary, and immune systems where key components of the host's cellular entry

machinery, ACE2 and TMPRSS2, were concordantly expressed. 